\title{
2,4-Thiazolidinedione Treatment Improves the Innate Immune Response in Dairy Goats with Induced Subclinical Mastitis
}

\author{
Fernanda Rosa, ${ }^{1}$ Johan S. Osorio, ${ }^{1}$ Erminio Trevisi, ${ }^{2}$ \\ Francisco Yanqui-Rivera, ${ }^{1}$ Charles T. Estill, ${ }^{1}$ and Massimo Bionaz ${ }^{1}$ \\ ${ }^{1}$ Department of Animal and Rangeland Sciences, Oregon State University, Corvallis, OR 97331, USA \\ ${ }^{2}$ Istituto di Zootecnica, Facoltà di Scienze Agrarie, Alimentari e Ambientali, Università Cattolica del Sacro Cuore, \\ 29122 Piacenza, Italy \\ Correspondence should be addressed to Massimo Bionaz; massimo.bionaz@oregonstate.edu
}

Received 13 February 2017; Accepted 30 April 2017; Published 27 June 2017

Academic Editor: Stéphane Mandard

Copyright (C) 2017 Fernanda Rosa et al. This is an open access article distributed under the Creative Commons Attribution License, which permits unrestricted use, distribution, and reproduction in any medium, provided the original work is properly cited.

\begin{abstract}
Mastitis is a major disease in dairy cows resulting in significant economic losses. In vitro works suggest that ruminants peroxisome proliferator-activated receptor gamma (PPAR $\gamma)$ can aid in improving the response to mastitis and can control milk fat synthesis. The objectives of the present experiment were to test if treatment with the putative PPAR $\gamma$ agonist 2,4-thiazolidinedione (TZD) improves (1) the response to subclinical mastitis and (2) milk fat production. Lactating goats received daily injections of $8 \mathrm{mg} / \mathrm{kg} \mathrm{BW}$ of TZD or saline for 3 weeks. After one week of TZD injection, half of the goats in each group received intramammary infusion of Strep. uberis or saline in both halves for a total of 4 groups ( $n=6 /$ group). TZD treatment did not affect milk fat but had positive effect on milk somatic cells count, blood nonesterified fatty acids, inflammatory markers, and liver function. TZD significantly increased myeloperoxidase but did not affect leukocytes phagocytosis or insulin. TZD increased adipocytes size and had minor effect on expression of PPAR $\gamma$ target genes in mammary epithelial cells but not in adipose tissue. Overall, TZD ameliorated the response to intramammary infection but the effect on milk fat synthesis and expression of related transcripts was less than expected.
\end{abstract}

\section{Introduction}

Mastitis is an inflammatory response of the udder to infection (usually bacteria) with detrimental consequences to animal well-being and milk quantity and quality [1-3]. It has been estimated that the cost of mastitis in the US dairy industry is ca. $\$ 2$ billion annually or $11 \%$ of total U.S. milk sales, with an average of ca. $\$ 179 /$ cow $[4,5]$.

Mastitis may be clinical or subclinical. Subclinical mastitis can be detected only by the measurement of somatic cells count (SCC) in milk, which increases several fold compared to milk from healthy mammary glands. The high SCC during subclinical mastitis negatively affects milk quality and reduces overall milk yield. It has been estimated that subclinical mastitis costs $\$ 130 /$ cow per year [1]. Considering approximately 9 million dairy cows in the US, the cost can be over $\$ 1$ billion/year. Therefore, prevention of subclinical mastitis is a priority for the dairy industry.
From a nutritional standpoint it is becoming evident that adequate levels of dietary antioxidants, particularly vitamin $\mathrm{E}$, selenium, zinc, and vitamin $\mathrm{A}$, reduce the incidence of environmental mastitis in dairy cows $[3,6,7]$. Besides providing protection from oxidative stress, several of these compounds enhance the mammary response to mastitis [6]. It is becoming increasingly evident that dietary compounds can profoundly alter the host's response via effect on the transcriptome [8-10]. Nutrigenomics is the discipline that studies such effect [11] and it is revolutionizing the field of nutrition [12]. Dietary compounds can affect the transcriptome via binding to transcription factors (TF) [11]. Peroxisome Proliferator-Activated Receptors (PPARs) are, among TF, the most interesting from a nutrigenomic standpoint $[11,13]$.

PPARs are nuclear receptors and members of the nuclear hormone receptor superfamily that work as TF. PPARs form a heterodimer with retinoid-X receptor (RXR) and, when activated by natural or synthetic agonists, modulate 
transcription by binding to a specific DNA sequence termed PPAR response element (PPRE) inducing the transcription of target genes [14]. Three PPAR isotypes denominated PPAR $\alpha$, $\operatorname{PPAR} \beta / \delta$, and PPAR $\gamma$ have been identified in several species, including bovine [13]. Among the three PPAR isotypes the $\operatorname{PPAR} \gamma$ is highly expressed in bovine white adipose tissue but its expression is also relatively abundant in mammary tissue [13]. Long-chain fatty acids (LCFA) are among the most potent agonists of bovine PPAR suggesting the possibility of dietary interventions to improve the response to diseases in dairy cows via activation of PPAR [13].

Furthermore, PPAR $\gamma$ plays a crucial role in the regulation of lipid and glucose metabolism [14] by regulating adipogenesis and lipogenesis [15] and by insulin-sensitizing effects [16]. The same functions of PPAR $\gamma$ appear to be conserved in ruminants [13].

In mammary tissue of dairy cows expression of PPAR $\gamma$ is upregulated from late pregnancy to early lactation [17] indicating a role of this nuclear receptor in controlling milk fat synthesis. This was supported by in vitro studies performed in cattle and goats [18-20] but not in mice [21], suggesting that the role of PPAR $\gamma$ in milk fat synthesis is likely ruminant-specific [13].

Besides a role in the regulation of milk fat synthesis, PPAR $\gamma$ may have also a positive role in the host's response to mammary infection, as reviewed recently [11, 22]. In nonruminants, PPAR $\gamma$ is known to have anti-inflammatory effects [23]. In bovine primary mammary epithelial cells (bMEC) the activation of PPAR $\gamma$ by several agonists caused downregulation of several proinflammatory cytokines and increased expression of the Chemokine (C-C Motif) Ligand 2 and Tumor Necrosis Factor alpha [24]. In contrast, activation of PPAR $\gamma$ by a natural agonist markedly enhanced the expression of both interleukin 8 and Chemokine $(\mathrm{C}-\mathrm{X}-\mathrm{C}$ motif) Ligand 6 but had no effect on other cytokines [24]. Interleukin 8 is the strongest chemoattractant for neutrophils and higher production is desirable for a quick response to intramammary infection $[25,26]$. In addition, intramammary infusion with Strep. uberis had a concomitant reduction of milk fat synthesis and downregulation of PPAR pathway in dairy cows [27]. The PPAR $\gamma$ may also play a role in tissue regeneration after mastitis because in monogastrics all PPAR isotypes play an important role in wound reepithelialization [28].

Our long-term goal is to improve the overall health and performance of dairy animals via nutrigenomic approaches. We have hypothesized that activation of various PPAR isotypes by LCFA can improve the transition from pregnancy to lactation in dairy cows [13]. The present work focuses on PPAR $\gamma$ and its role on mammary response to infection and milk fat synthesis. Our hypotheses are that activation of PPAR $\gamma$ (1) improves the response to mammary infection and (2) augments synthesis of milk fat. To assess these hypotheses we performed a proof-of-concept study using a putative synthetic PPAR $\gamma$ agonist with the objective to test if activation of PPAR $\gamma$ prior to and during induced subclinical mastitis (1) improves the response to mastitis and (2) affects milk fat synthesis in dairy goats.

\section{Materials and Methods}

2.1. Experiment Design and Animal Management. The Institutional Animal Care and Use Committee (IACUC) of Oregon State University approved all procedures for this study (protocol \# 4448). An overview of the experimental design is depicted in Figure 1. Twenty-four lactating Saanen goats (mean \pm SD; age $5.1 \pm 0.6$ years old, $3.6 \pm 0.6$ lactations, $156 \pm 14$ day in milk, $68.1 \pm 7.6 \mathrm{~kg}$ of BW, and $1.6 \pm 0.5$ body condition score [1-5 scale]), negative to a milk bacterial analysis, were purchased from a commercial farm (Tumalo Farm, Bend, Oregon, USA) and housed in the Oregon State University Sheep Center facility. One week of adaptation to the new environment was allowed prior to starting the experiment. The goats were assigned to treatments in a randomized block design (blocked by body condition score, body weight, milk yield, and milk components) and housed in 4 separate pens (6 goats/pen). Animals were fed twice a day (8 AM and 6 PM) with a diet similar to what was fed at the farm of origin with ad libitum hay (approx. 50\% orchard hay and 50\% alfalfa). The goats received approximately $150 \mathrm{~g}$ of a commercial grain goat mix (Kountry Buffet, PayBack, Harrisburg, OR) during milking. The goats were milked once a day at 8 AM in a stanchion using a portable milking machine. Teats of the goats were predipped before milking and postdipped after milking using $0.5 \%$ iodine solution.

2.2. Treatments. After the week of adaptation, goats were fitted with an indwelling jugular catheter (Cat\# 017376, Henry Schein, USA) with an extension set (Cat\# 005642, Henry Schein). Originally the catheter was kept in place and hidden from the goats using Elastikon stretch bandage (Cat\# 000925, Henry Schein); after one week a bandage of VetWrap $4^{\prime \prime}$ was used for practicality. The catheter was flushed twice a day using $10 \mathrm{~mL}$ of heparinized saline (2 i.u./mL). The day after catheter insertion, 12 goats received daily injection of $8 \mathrm{mg} / \mathrm{kg}$ of BW of 2,4-thiazolidinedione (TZD; Cat\# 375004, Sigma-Aldrich, USA) in $10 \mathrm{~mL}$ sterile physiological saline (VINV-SALN-1000, Henry Schein) throughout the entire study period (20 days). The other goats $(n=12$; CTR) received $10 \mathrm{~mL}$ of physiological saline. The daily injection was performed at $12 \mathrm{PM}$. The dose of TZD was selected based on the reported efficacy of $4 \mathrm{mg} / \mathrm{Kg} \mathrm{BW}$ in dairy cows [29] and the faster drug clearance of dairy goats [30] that requires typically doubling the dose of many drugs for this species compared to bovine.

2.3. Intramammary Infusion of Streptococcus uberis. After one week of TZD or saline injection, half of the goats in each treatment received an intramammary infusion (IMI) of $1.7 \times 10^{8}$ Streptococcus uberis (Strep. uberis) in $10 \mathrm{~mL}$ sterile physiological saline in each of the mammary halves (the groups were mastitis control or MCTR and mastitis TZD or MTZD) following a previously published protocol [31]. The remaining goats received an intramammary infusion of $10 \mathrm{~mL}$ sterile physiological saline (control saline or CTRL and control TZD or CTZD) in each half gland. The aliquots of Strep. uberis in $1.5 \mathrm{~mL}$ sterile vials were provided by the laboratory of Peggy Dearing, College of Veterinary Medicine, 


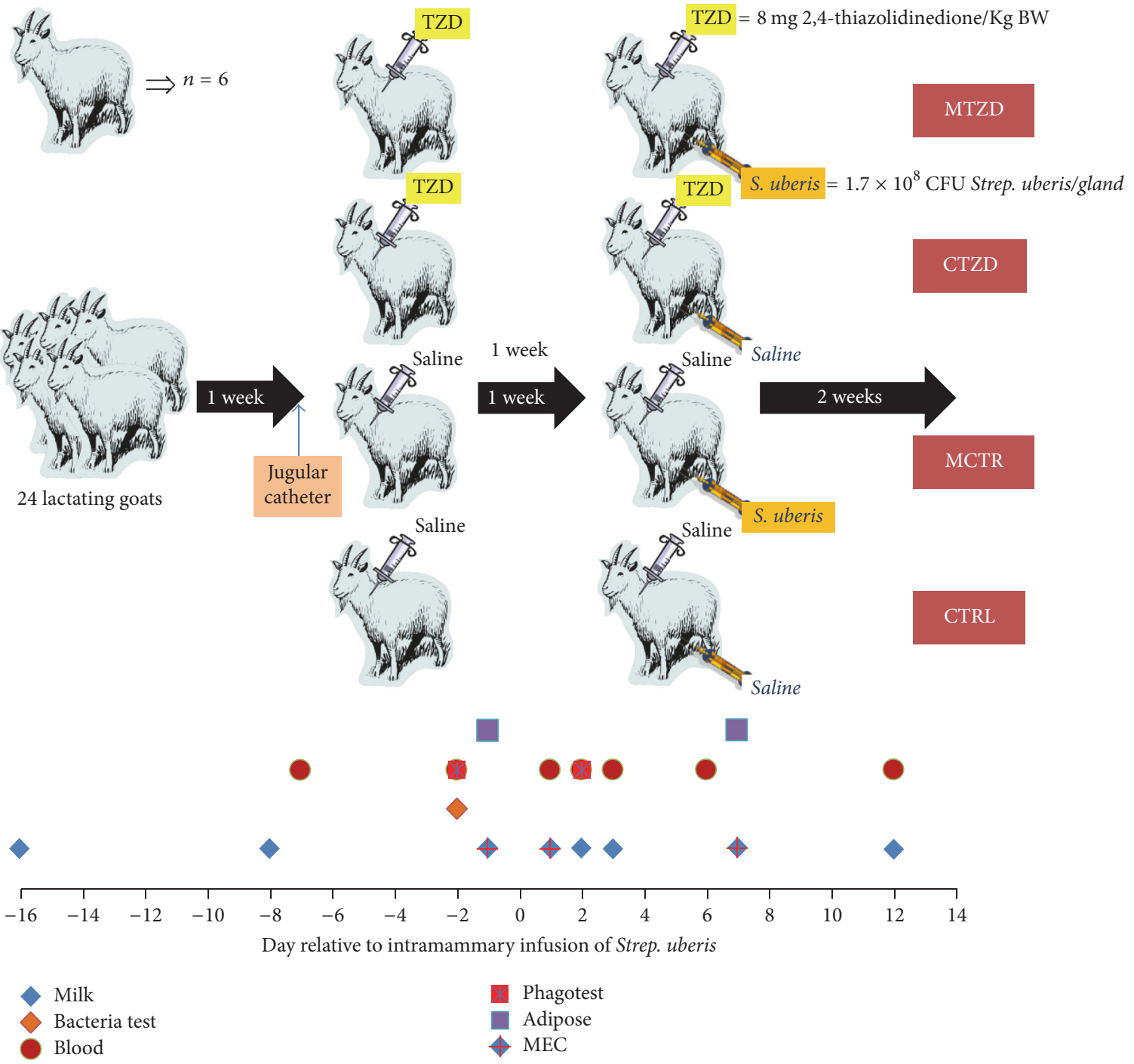

FIgURE 1: Overview of the experimental design with time points for collection of samples. MEC = mammary epithelial cell isolation.

Oregon State University. The intramammary infusion was performed just after the morning milking after carefully cleaning the teat ends with individual moistened towels and disinfecting them with swabs containing $70 \%$ ethanol. The infusion was performed with the aid of a disposable sterile urinary catheter (TomCat, USA). After IMI, each mammary half was thoroughly massaged upward into the gland cistern for approximately $20 \mathrm{~s}$ to distribute the inoculum.

The Strep. uberis used in the present experiment was isolated from a mastitic cow and the strain determined using DNA isolated from the bacteria using a DNA Clean \& Concentrator-5 (cat\# D4013, Zymo Research, Tustin, CA) and submitted for Sanger sequencing at Center for Genome Research and Biocomputing at Oregon State University. The sequencing result was blasted against all bacteria sequences using BLASTN 2.4.0 at National Center for Biotechnology Information. The sequence had $89 \%$ identity with Strep. uberis strain 0140J (File S1 in Supplementary Material available online at https://doi.org/10.1155/2017/7097450).
2.4. Follow-Up Study. Two animals in the MTZD group ceased to produce milk after IMI and had increase in temperature $>41^{\circ} \mathrm{C}$. For this reason the animals had to be removed from the study; thus, the MTZD groups had only 4 animals. This event raised the possibility that the cause of agalactia was the interaction between TZD injection and IMI. In order to test this we performed a follow-up study using 4 animals from the CTZD and 4 animals from the CTRL. The study followed the same protocols as the main study. In the present paper the data from the follow-up study are not reported, with the exception of frequency of agalactia.

2.5. Measurements and Sample Collection. Milk was collected aseptically from both halves of the mammary for bacterial analysis at the time of purchase, 3 days prior to IMI, and just before IMI. Before sampling, the teat was treated with teat dip solution and cleaned using disposable paper towels. The orifice of the teat was disinfected with swabs containing $70 \%$ ethanol, first stripped milk was discarded, and approximately 
$1 \mathrm{~mL}$ of milk was collected in sterile $1.5 \mathrm{~mL}$ tubes. The samples were immediately put on ice and shipped within 4 hours to the Ag Health Laboratories, Inc. (Sunnyside, WA), for bacterial culture blood agar plates. All samples were negative to Strep. uberis. To ascertain SCC status a California Mastitis Test was performed at the last milking prior to IMI.

Milk yield was recorded daily throughout the experiment. Milk samples were collected for component analysis 5 days prior to treatment assignment and then the day before starting TZD injections, the day before IMI, and 1, 2, 3, 5, 7 , and $12 \mathrm{~d}$ after IMI. Samples were collected and shipped to the Willamette National Dairy Herd Information Association (DHIA, Salem, OR) using $10 \mathrm{~mL}$ vials provided by the DHIA containing Bronopol. SCC, lactose, fat, and protein were measured in milk. The energy corrected milk (ECM) was calculated using the equation $(0.327 \times \mathrm{kg}$ of milk $)+(12.95$ $\times \mathrm{kg}$ of fat $)+(7.65 \times \mathrm{kg}$ of protein $)$ [32]

Rectal temperature was checked daily using a rectal thermometer prior to and after IMI and every hour during the first $6 \mathrm{~h}$ after IMI and approximately every $8 \mathrm{~h}$ until $114 \mathrm{~h}$ after IMI. Body weight (BW) was recorded weekly throughout the study.

Blood samples were collected prior to the morning feeding from the jugular vein using a 20-gauge BD Vacutainer needle (Becton Dickinson, Franklin Lakes, NJ). The blood was collected just before starting the TZD injections (i.e., 7 days prior to IMI or baseline), 2 days prior to IMI (5 days into TZD injections), every day during the first 3 days after IMI (i.e., $24 \mathrm{~h}, 48 \mathrm{~h}$, and $72 \mathrm{~h}$ after IMI), and at 6 and $12 \mathrm{~d}$ after IMI. Samples were collected into evacuated tubes $\left(10 \mathrm{~mL}, \mathrm{BD}\right.$ Vacutainer ${ }^{\circledR}$, Becton Dickinson, Franklin Lakes,
NJ) containing either serum clot activator or sodium heparin. After blood collection, tubes containing sodium heparin were placed on ice, while the tubes with clot activator were kept at room temperature $(\sim 30 \mathrm{~min})$ until centrifugation in a $\mathrm{C} 3$ Select centrifuge (LW Scientific) and frozen at $-20^{\circ} \mathrm{C}$ until being analyzed.

2.6. Blood Metabolites and Inflammatory Markers. Aliquots of plasma and serum were shipped on dry ice to the Istituto di Zootecnica, Università Cattolica del Sacro Cuore, Piacenza, Italy, for metabolic and inflammatory profiling. Blood samples were analyzed for 19 parameters. These include the metabolic parameters glucose, cholesterol, urea, calcium, magnesium, nonesterified fatty acids (NEFA), triacylglycerol (TG), $\beta$-hydroxybutyric acid (BHBA), and retinol and the inflammatory-related parameters albumin, haptoglobin, ceruloplasmin, paraoxonase, myeloperoxidase, total bilirubin, total reactive oxygen metabolites (ROMt), zinc, and $\alpha$ tocopherol plus the liver parameter gamma-glutamyl transferase $(\gamma \mathrm{GT})$. The analyses were performed using a clinical autoanalyzer (ILAB 650, Instrumentation Laboratory, Lexington, MA) and HPLC following procedures described previously [33-35].

2.7. Insulin, QUICKI, and RQUICKI. Concentration of insulin was analyzed in plasma 5 days after TZD injection (i.e., $-2 \mathrm{~d}$ relative to $\mathrm{IMI}$ ) and $3 \mathrm{~d}$ after IMI using a commercial ELISA assay kit (NeoScientific Cat\# GTI0011) following the manufacturer instruction. The Quantitative Insulin Sensitivity Check Index (QUICKI; [36]) and the Revised QUICKI (RQUICKI; [37]) were calculated as follows:

$$
\begin{aligned}
\text { QUICKI } & =\frac{1}{[\log (\text { fasting insulin } \mu \mathrm{U} / \mathrm{mL})+\log (\text { fasting glucose } \mathrm{mg} / \mathrm{dL})]} \\
\text { RQUICKI } & =\frac{1}{[\log (\text { fasting insulin } \mu \mathrm{U} / \mathrm{mL})+\log (\text { fasting glucose } \mathrm{mg} / \mathrm{dL})+\log (\mathrm{NEFA} \mathrm{mmol} / \mathrm{l})]} .
\end{aligned}
$$

2.8. Phagocytosis and \% Granulocytes. The phagocytic capacity of leukocytes isolated from $100 \mu \mathrm{L}$ heparinized whole blood was determined at -2 and $1 \mathrm{~d}$ relative to IMI using Phagotest kit (Glycotope Biotechnology, Heidelberg, Germany) following the manufacturer's instructions but using half the amount of each reagent. The use of half of each reagent had an approximately 5\% consistent reduction of phagocytosis (Figure S1). The \% of polymorphonuclear cells (PMN or granulocytes) was assessed by using side scatter and forward scatter after gating on nucleated cells on FL2 (i.e., DNA staining solution). Percentage phagocytosis on all leukocytes, PMN, and monocytes was determined (Figure S2).

2.9. Adipose Biopsy. Subcutaneous adipose tissue was collected by biopsy from alternate sides of the tail-head $1 \mathrm{~d}$ before and $7 \mathrm{~d}$ after IMI (Figure 1). The biopsy was performed as previously described [38] with modifications. Briefly, the clipped tail-head area was thoroughly scrubbed with poviderm scrub (Povidone Henry Schein Inc., USA) and 2\% lidocaine (Henry Schein Inc., USA) was injected subcutaneously in the area of incision. A 4 to $5-\mathrm{cm}$ incision was made to expose the tissue which was collected using sterile forceps and a scalpel. The incision was sutured closed. Biopsied tissue was placed in a sterile Petri dish containing gauze sprayed with RNAse Zap (ThermoFisher, USA). Connective tissue and large vessels were dissected out using a sterile scalpel blade and the tissue was washed using a sterile physiological saline solution with the aid of a disposable sterile syringe. The cleaned tissue was dissected into 3 pieces. Two pieces were transferred to $2.0 \mathrm{~mL}$ self-standing cryovials (cat\#, 26-201, Genesee Scientific, USA) and put in a foam box with dry ice for transport to the laboratory and then stored at $-80^{\circ} \mathrm{C}$ until analysis. The other piece was put in a $1.5 \mathrm{~mL}$ tube containing $10 \%$ neutral buffered formalin (\#16004-126, VWR, USA) to be fixed for histological analysis. 
2.10. Mammary Epithelial Cells Isolation. The mammary epithelial cells (MEC) were isolated from $50 \mathrm{~mL}$ of milk using magnetic sorting. The milk sample was collected in $50 \mathrm{~mL}$ sterile tubes (cat\# 89004-364, VWR, USA) and immediately preserved on ice until isolation (approximately $1 \mathrm{~h}$ later). Tubes were centrifuged at $1,000 \times \mathrm{g}$ at $4^{\circ} \mathrm{C}$ for $10 \mathrm{~min}$ to separate the fat and pellet the cells. Cells were washed twice with $10 \mathrm{~mL}$ of sterile PBS and centrifuged at $500 \times \mathrm{g}$ at $4^{\circ} \mathrm{C}$ for $5 \mathrm{~min}$. Before the last wash the cells were counted using a MOXI Z Mini Automated Cell Counter (Orflo Technologies, USA). The final pellet was resuspended in $500 \mu \mathrm{L}$ of a PBS solution plus $0.1 \%$ bovine albumin and transferred in a $1.5 \mathrm{~mL}$ tube prewetted with the PBS $+0.1 \%$ albumin solution. An antibody against the epithelial-specific marker mucin 1 (NBP1-60046, Novus Biologicals, USA) [39] conjugated with Pierce Protein AG Magnetic Beads (ThermoFisher, USA) was added $\left(1 \mu \mathrm{L} / 10^{6}\right.$ cells). Samples were incubated for $30 \mathrm{~min}$ on ice in a shaker and cells were washed once using PBS and immediately isolated using an autoMACS separator (Miltenyi Biotec, USA). The positive and the negative separated cells were stored at $-80^{\circ} \mathrm{C}$ until RNA extraction. The evaluation of the enrichment of mammary epithelial cells was performed on 5 positive and 5 negative cells from 5 random milk samples measuring expression of casein kappa (CSN3) and lactalbumin (LALBA) on MUC1 positive and MUC1 negative cells. Overall, the use of MUC1 antibody tended to be enriched for cells expressing higher amount of the mammary-specific genes casein $\kappa(C S N 3)$ and lactalbumin (LALBA) plus mucin 1 (MUC1) (Figure S3). Normalization of transcript abundance was performed as described below.

2.11. RNA Isolation and Reverse Transcription Quantitative Polymerase Chain Reaction (RT-qPCR). RNA extraction was performed using RNA Clean \& Concentrator ${ }^{\mathrm{TM}}-5$ (cat\# R1013, Zymo Research, USA) following the vendor protocol. Prior to RNA extraction, the adipose tissue was disrupted using a Bullet Blender Next Advance (Laboratory Instruments, USA). RNA was quantified with a Nanodrop ND-1000 spectrophotometer (NanoDrop Technologies, Wilmington, DE). RNA integrity was assessed using a 2100 Bioanalyzer Instrument (Agilent, USA) by the Center for Genome Research and Biocomputing at Oregon State University. For the MEC the $260 / 280$ ratio was $1.9 \pm 0.4$ (mean \pm SD) and the RNA Integrity Number (RIN) was $4.7 \pm 2.1$, with a range from 1 to 9.2. For the adipose tissue the $260 / 280$ ratio was $1.8 \pm 0.2$ (mean \pm SD) and the RIN was $4.0 \pm 2.0$, with a range from 1 to 9.0 .

Primers were designed using Primer Express 3 and tested as previously described [40] (Table S1 in File S2) with modifications. Briefly, Capra hircus specific sequences were searched in the National Center for Biotechnology Information (NCBI at https://www.ncbi.nlm.nih.gov/) and blasted against the sheep genome on the University of California Santa Cruz Genome Browser (https://genome.ucsc.edu/) in order to determine the exon-exon junctions. Primer-pairs were blasted using NCBI BLASTN tool. Amplicon from each primer-pair was cleaned using DNA Clean \& Concentrator5 (Zymo Research. USA) and sent to the Center for Genome Research and Biocomputing at Oregon State University for sequencing. Results of sequencing are available in Table S2 in File S2.

Despite the low RIN numbers we proceeded with the RT-qPCR analysis (see Results). Six potential internal control genes (ICG) were tested [i.e., glyceraldehyde 3phosphate dehydrogenase (GAPDH), ribosomal protein S9 (RPS9), ubiquitously expressed transcript (UXT), tyrosine 3-monooxygenase/tryptophan 5-monooxygenase activation protein zeta polypeptide (YWHAZ), glucose-6-phosphate dehydrogenase (G6PD), and mitochondrial ribosomal protein L39 (MRPL39)] based on prior publications [40, 41] using geNorm [42]. For adipose tissue the most reliable normalization factor using the above ICG was obtained $(V$ value $=0.23$ ) by using 5 ICG (all the ICG tested except $M R P L 39$ ). For the MEC 3 ICG (GAPDH, RPS9, and YWHAZ; $V$-value $=0.26)$ were used to calculate the normalization factor. Target transcripts measured were related to lipid synthesis, PPAR $\gamma$ activation, and inflammation. In particular we measured, in both MEC and adipose tissue, the abundance of PPAR $\gamma$ transcript (PPARG) and the PPAR $\gamma$ putative targets Lipoprotein Lipase (LPL) and Fatty Acid Synthase (FASN). In adipose tissue we also measured transcription of Acetyl-CoA Carboxylase Alpha (ACACA), Sterol Regulatory Element Binding Transcription Factor 1 (SREBF1), and Tumor Necrosis Factor alpha (TNFA). For MEC we measured transcription of MUC1, Interleukin 8 (IL8), and Chemokine (C-C Motif) Ligand 2 (CCL2). The RT-qPCR analysis was performed as previously described [40] with some modifications. Briefly, RevertAid (ThermoFisher, USA) was used as reverse transcriptase following manufacturer's indication and Power SYBR Green Master Mix (ThermoFisher, USA) was used for the qPCR. The PCR reaction was performed in a $7900 \mathrm{HT}$ (Applied Biosystems, USA) in MicroAmp ${ }^{\circledR}$ Optical 384-Well Reaction Plate (Applied Biosystems, USA). The reaction was as follows: $2 \mathrm{~min}$ at $50^{\circ} \mathrm{C}, 10 \mathrm{~min}$ at $95^{\circ} \mathrm{C}$, and 40 cycles with $15 \mathrm{~s}$ at $95^{\circ} \mathrm{C}$ followed by $1 \mathrm{~min}$ at $60^{\circ} \mathrm{C}$. A dissociation curve was performed (gradient from $60^{\circ} \mathrm{C}$ to $95^{\circ} \mathrm{C}$ ) to check for amplicon quality. Final qPCR data were obtained by using a 6-point 2-fold dilution standard curve. The RT-qPCR was performed following MIQE guidelines [43].

2.12. Histological Analysis of the Adipose Tissue. Adipose tissue samples preserved in $10 \%$ neutral buffered formalin were immersed in $15 \%$ and then in $30 \%$ diluted sucrose in PBS before cutting in cryostat sections of $15-\mu \mathrm{m}$ thickness at a temperature of $-27^{\circ} \mathrm{C}$. Prior to $\mathrm{H} \& \mathrm{E}$ staining, sections were washed in PBS buffer followed by rinse in water for 30 s. Next, sections were incubated with Harris' Hematoxylin (VWR, US, Cat. number 95057-858) solution for 3 min and rinsed afterwards with warm water for $25 \mathrm{~s}$. The sections were submerged in eosin solution and rinsed with PBS for $1 \mathrm{~min}$. Tissue was washed in $80 \%$ ethanol for $1 \mathrm{~min}$ and finally immersed in xylene for $10 \mathrm{~s}$, mounted in a microscope slide, and imaged with a 10x magnification objective using a Leica DM6000 microscope (Leica Microsystems Inc., IL, USA). The analysis of adipocytes size was performed using CellProfiler 2.1.1 software (http://cellprofiler.org/) [44]. Besides average area of adipocytes, the frequency of various ranges of area and diameter of adipocytes was measured to estimate the 
formation of new adipocytes (i.e., small size) and formation of large adipocytes, that is, accumulating large amount of stored triglycerides.

2.13. Statistical Analysis. Prior to statistical analysis data were checked for outliers using PROC REG of SAS 9.2 (SAS Institute, Inc., Cary, NC, USA). Data with a studentized $t>$ 3.0 were removed. Normal distribution was assessed using PROC UNIVARIATE of SAS. Data with a Shapiro-Wilk test of $P<0.01$ and statistic $<0.90$ and a Kolmogorov-Smirnov $P<0.01$ were considered not normally distributed and were $\log _{2}$ or square root transformed prior to statistical analysis. Data were analyzed with the PROC GLIMMIX procedure of SAS 9.2. Fixed effects in the model were TZD (Z), time $(\mathrm{T})$, mastitis $(\mathrm{M})$, and all interactions with goat as random effect. Due to the irregular timeline of each measurement, the covariance structure SP (POW) for repeated measures was used for analysis. Statistical significance and tendencies were declared at $P \leq 0.05$ and $P \leq 0.10$, respectively.

In order to account and correct for difference between groups at baseline (for blood parameters and milk yield it was $-7 \mathrm{~d}$ and for milk composition it was $-8 \mathrm{~d}$ relative to IMI), a statistical analysis of $\mathrm{Z}, \mathrm{M}$, and $\mathrm{Z} \times \mathrm{M}$ was performed for the milk and blood metabolic parameters. If a difference with $P<0.2$ in any of the parameters analyzed was observed, data for each sample were corrected arithmetically to obtain the same average between groups at baseline. This was performed by subtracting to each sample the difference between the average at baseline between the CTRL group and the sample's group (i.e., all data were corrected by the CTRL group at baseline). This approach was chosen instead of the classical covariate model at baseline in order to have the averagecorrected LSmeans data with standard error at baseline for each group. The corrected dataset was used for the statistical analysis.

The statistical analysis of overall mean adipocyte size was performed using the above model. In order to evaluate the effect in each range of adipocyte areas or diameters, the statistical analysis using the above model was performed for each range. When range and time were combined, the model included $\mathrm{Z}, \mathrm{M}, \mathrm{T}$, and range and all interactions as main effects.

\section{Results}

Two animals in the MTZD group were removed from the study because they ceased to produce milk after IMI. For this reason we had only $n=4$ for the MTZD groups. The effect however was not due to an interaction between TZD injection and IMI because, in the follow-up study performed, 1 out of 4 animals in the control group ceased completely milk production after IMI while all of the TZD-treated animals continued to milk. The reason for agalactia in the two animals in TZD group in the main study remains unclear. Five days after IMI a few goats had issues with the catheter (either the catheter was dislodged or was chewed by other goats) and it needed to be removed. In order to keep all the treatments consistent we removed the catheter from all the animals and we injected the 2,4-TZD directly into the jugular vein until the end of the trial.

3.1. Rectal Temperature and Body Weight. The rectal temperature overall declined in the first 5 hours after IMI in all groups but increased significantly afterwards until 44 hours after IMI, especially in the animals treated with Strep. uberis (Figure 2). The rectal temperature tended to remain higher in the MCTR group compared to the other groups until it reached a significantly higher value compared to all the other groups at $114 \mathrm{~h}$ (approx. $5 \mathrm{~d}$ ) after IMI (Figure 2). Temperatures in the MTZD group were similar to the CTRL and CTZD groups within $68 \mathrm{~h}$ after IMI. Overall the CTZD group had a more stable and lower temperature compared to all the other groups, including CTRL, especially at $44 \mathrm{~h}$ after IMI where a significant increase in body temperature was observed for the CTRL animals. Body weight was not affected by TZD or mastitis (Figure S4).

3.2. Milk Yield and Composition. In Figure 3 is depicted the trend for SCC and milk yield. SCC was overall significantly higher in the groups receiving Strep. uberis (i.e., MTZD and MCTR) compared to the groups receiving intramammary infusion of saline at the beginning of the trial, but the differences disappeared just before IMI. Due to IMI, the MTZD and MCTR groups had a significantly larger increase in SCC (13.9- and 11.3-fold, resp., from -1 to 2 days after IMI) than the control groups (1.3 for CTRL and 1-fold for CTZD). The SCC remained higher in MCTR and MTZD compared to CTRL and CTZD until the end of the trial. A tendency for a $\mathrm{Z} \times \mathrm{M} \times \mathrm{T}$ was detected due to an overall lower SCC for the animals receiving TZD, especially for the CTZD group during the first 2 days after IMI.

Despite the significant difference observed at $-8 \mathrm{~d}$, which would have prompted us to correct the data based on the criteria utilized in the present work, we decided to show the original SCC data due to the practical importance of the SCC data for farmers; however, when the data were adjusted at $-8 \mathrm{~d}$, the MCTR had an overall larger SCC compared to all groups, including MTZD (Figure S5).

The milk yield at baseline was $1.12 \pm 0.35 \mathrm{~kg} / \mathrm{d}$. A significant effect of $\mathrm{M} \times \mathrm{T}$ was detected due to an overall decrease in milk yield by the goats treated with Strep. uberis compared to goats receiving intramammary saline (Figure 3 ). A tendency for the interaction $\mathrm{Z} \times \mathrm{M} \times \mathrm{T}(P=0.08)$ was detected for milk yield. Strep. uberis intramammary infusion decreased milk yield in the MCTR group, while the MTZD had only a numerical decrease in milk yield.

The other milk parameters (Figure 4) were not affected by IMI or TZD except \% protein, which was higher in Strep. uberis treated goats after IMI likely driven by the higher SCC, and $\%$ of milk lactose, which was higher for TZD-treated animals after IMI. Even though not statistically significant, the milk fat yield was numerically lower in MCTR after IMI. The ECM was not significantly affected by treatments but a tendency for $\mathrm{M} \times \mathrm{Z} \times \mathrm{T}$ was detected due to a decrease in ECM in MCTR but not in the other groups (Figure S6). 


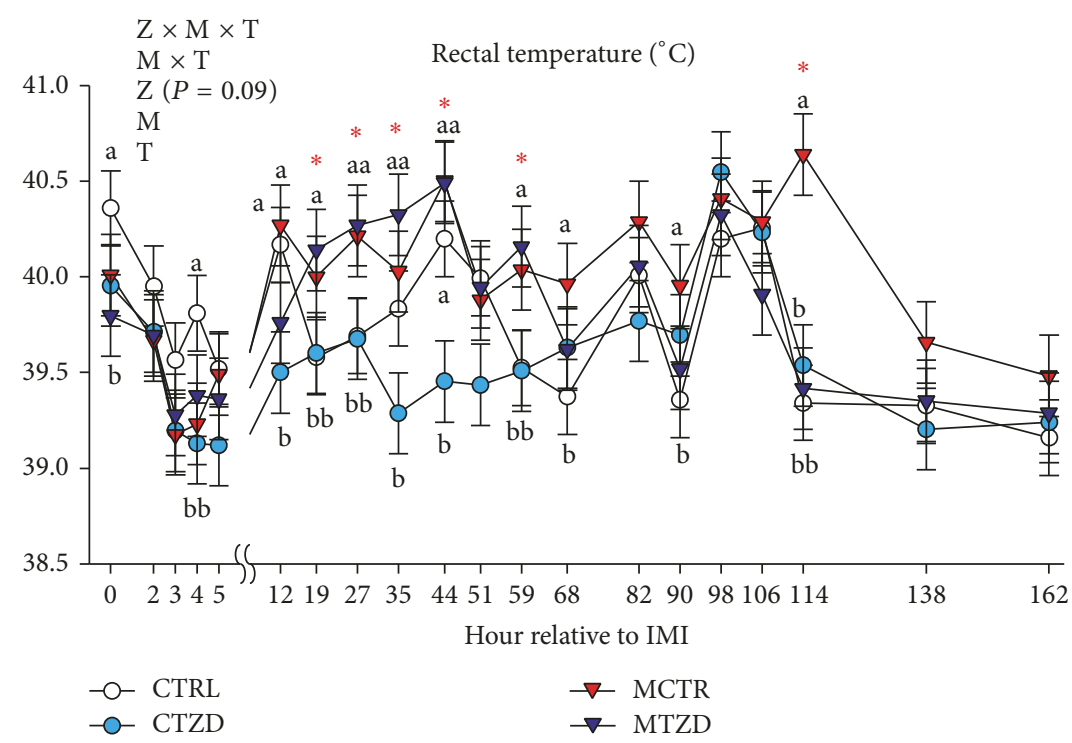

FIGURE 2: Rectal temperature recorded for several hours after intramammary infusion (IMI) of Strep. uberis (M) or saline in goats receiving daily intrajugular injection of 2,4-thiazolidinedione (TZD) or saline (CTR). Significant $(P \leq 0.05)$ effects and interactions are indicated in the graph (mastitis: M, time: T, and TZD: Z). The $P$ value for tendency of TZD effect is reported. Significant effect of $M \times T$ is denoted with red asterisk and different letters denote significant differences. Letters denoted significant differences between groups at the same time point.

3.3. Blood Metabolic Parameters. Glucose concentration was not affected by TZD but overall higher glucose was detected after IMI in animals receiving Strep. uberis, mostly due to a large increase in glycaemia in MCTR group whereas the MTZD group did not have any difference from the nonmastitis groups (Figure 5). We observed an overall increase in NEFA due to IMI in all groups except CTZD (Figure 5). The non-TZD-treated animals had a more persistent increase in NEFA after IMI compared to TZD-treated animals. Overall, NEFA tended to be lower in TZD-treated animals. All animals had a decrease in BHBA after IMI and an overall lower value for TZD was observed at $12 \mathrm{~d}$ after IMI (Figure 5). The concentration of triacylglycerol (TG) was not affected by $\mathrm{Z}$ or $\mathrm{Z} \times \mathrm{T}$ but tended to be higher $(P=0.06)$ in Strep. uberus treated animals after IMI (Figure 5).

A trend $(P=0.09)$ for TZD, mastitis, and full interaction $\mathrm{Z} \times \mathrm{M} \times \mathrm{T}$ resulted in the MTZD group with a greater urea concentration than the other groups on $\mathrm{d}$ 1, 6, and 12 after IMI (Figure S7). After IMI in all groups $\alpha$-tocopherol decreased significantly with no differences between groups (Figure S7).

Administration of TZD had no effect on plasma insulin concentrations, QUICKI, or RQUICKI, although a numerically larger QUICKI was detected for TZD-treated versus control goats (Figure S8). The statistically significant effect of mastitis on insulin was also observed prior to IMI; thus, it cannot be considered biologically relevant (Figure S8).

3.4. Blood Minerals. The Ca was increased in TZD-treated goats prior to IMI and tended to remain higher compared to the non-TZD-treated goats after IMI mainly due to higher Ca concentration in MTZD-treated goats (Figure 6). The concentration of $\mathrm{Zn}$ tended $(P=0.08)$ to be higher in TZD-treated compared to non-TZD-treated goats and was overall higher in the former compared to the latter after IMI
(Figure 6). Zn concentration was larger in MTZD compared to the other groups at $\mathrm{d}-2$ and 6 relative to IMI but the $\mathrm{Zn}$ was higher in CTZD animals at $12 \mathrm{~d}$ after IMI. As for Ca, the observed pattern of $\mathrm{Zn}$ in blood was mostly driven by MTZD group. The Mg level decreased after IMI but no differences between groups were detected (Figure 6).

3.5. Inflammation and Liver Stress. The level of the positive acute phase protein (+APP) haptoglobin was $0.30 \pm 0.25 \mathrm{~g} / \mathrm{L}$ (mean \pm SD) seven days prior to IMI with a significantly lower overall level in TZD-treated versus control animals after 1 week of TZD treatment (Figure 7). Haptoglobin level rose rapidly after IMI in all animals, reaching values $>2 \mathrm{~g} / \mathrm{L}$ with an overall larger persistence of high levels in Strep. uberis treated animals, mostly due to MCTR group (Figure 7). The other measured + APP, ceruloplasmin, was increased over time after IMI in all groups without being significantly affected by TZD or IMI but with numerically lower values in TZD-treated goats versus control at the end of the trial (Figure S9).

The marker of neutrophils killing capacity myeloperoxidase was overall lower in TZD-treated compared to control goats after 1 week of TZD treatment but increased significantly in TZD-treated goats after IMI and was higher compared to control groups until the end of the experiment (Figure 7). The CTZD had an overall higher myeloperoxidase compared to the other groups. The liver stress marker $\gamma \mathrm{GT}$ was not different between groups prior to IMI but was overall higher in TZD-treated versus control animals after IMI. The post-IMI difference was mostly due to an increase of the parameter in CTZD $6 \mathrm{~d}$ after IMI (Figure 7).

Among the indexes of negative acute phase reaction, albumin was only affected by time with numerically higher values in TZD-treated goats after IMI whereas total cholesterol decreased after IMI in non-TZD-treated groups with 

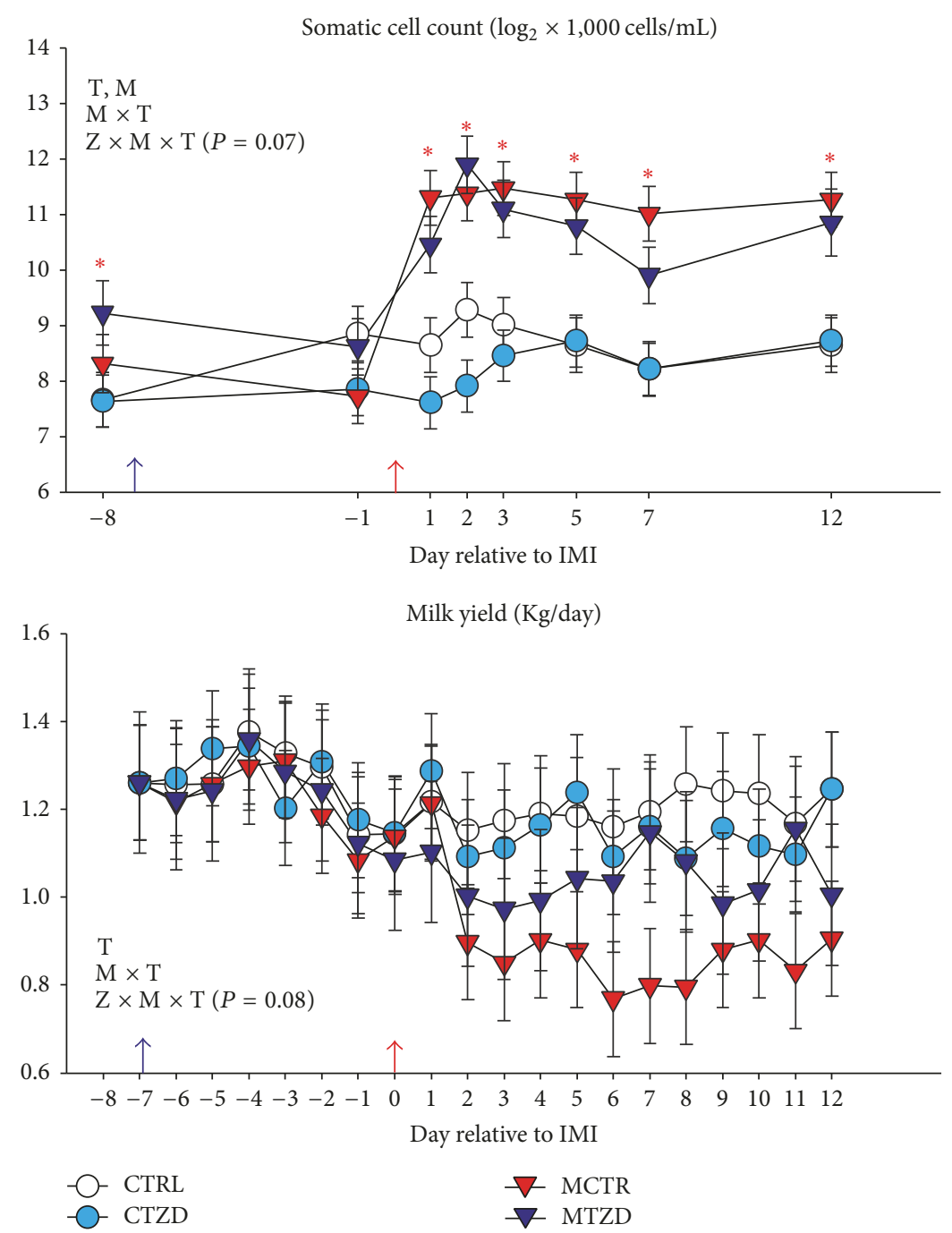

FIGURE 3: Milk somatic cell count and milk yield measurements from -8 to $12 \mathrm{~d}$ relative to intramammary infusion of Strep. uberis (M) or saline in goats receiving daily intrajugular injection of 2,4-thiazolidinedione (TZD) or saline (CTR). Significant $(P \leq 0.05)$ effects and interactions are indicated in the graph (mastitis, $M$, time: T, and TZD, Z). The $P$ value for tendency is reported. Significant effect of $M \times T$ is denoted with red asterisk.

significantly lower values compared to TZD-treated goats at $6 \mathrm{~d}$ after IMI (Figure 7). Retinol tended to be affected by $\mathrm{M}$ $\times \mathrm{T}$ and $\mathrm{Z} \times \mathrm{T}$ interactions mostly due to higher values in MTZD at $-2 \mathrm{~d}$ day relative to IMI and lower values in MCTR at $6 \mathrm{~d}$ after IMI compared to the other groups (Figure 7). In contrast, the activity of the negative acute phase protein and antioxidant paraoxonase and the total bilirubin, as an index of liver clearance capability, decreased in all groups after IMI without being affected by TZD treatment (Figure S9). The total reactive oxygen metabolites increased in all goats after IMI without being affected by TZD (Figure S9).

3.6. \% PMN and Phagocytosis in Blood. The \% PMN was $62.5 \pm 1.7$ (mean \pm SEM) before IMI and was not different between groups. After IMI the \% PMN was decreased in all groups (Figure 8). The goats treated with Strep. uberis had a larger decrease in the proportion of PMN compared to the goats receiving intramammary saline (Figure 8 ). The $\%$ phagocytosis of all leukocytes and PMN was only affected by time but was not affected by TZD or mastitis while monocyte phagocytosis was reduced by Strep. uberis infusion (Figure 8).

3.7. Gene Expression. A negative correlation between cycle to threshold $(\mathrm{Ct})$ or cycle to quantity $(\mathrm{Cq})$ values and RIN has been reported in several publications $[45,46]$. This is due to the decrease in abundance of integer mRNA in samples with higher degradation (i.e., lower RIN) resulting in higher $\mathrm{Ct}$ ( or Cq) values. Based on such correlation, a $\mathrm{RIN} \geq 5$ was suggested as adequate for RT-qPCR analysis [45]. Due to the large proportion of samples with a RIN $<5$ in both adipose tissue (60\%) and MEC (50\%), most of our samples would have been inadequate for RT-qPCR. The reason for such large proportion of samples with a low RIN is unclear, because samples were snapped frozen on dry ice and kept at $-80^{\circ} \mathrm{C}$ during storage and in ice during analyses. Despite the low RIN, we tested if the degradation observed with the 

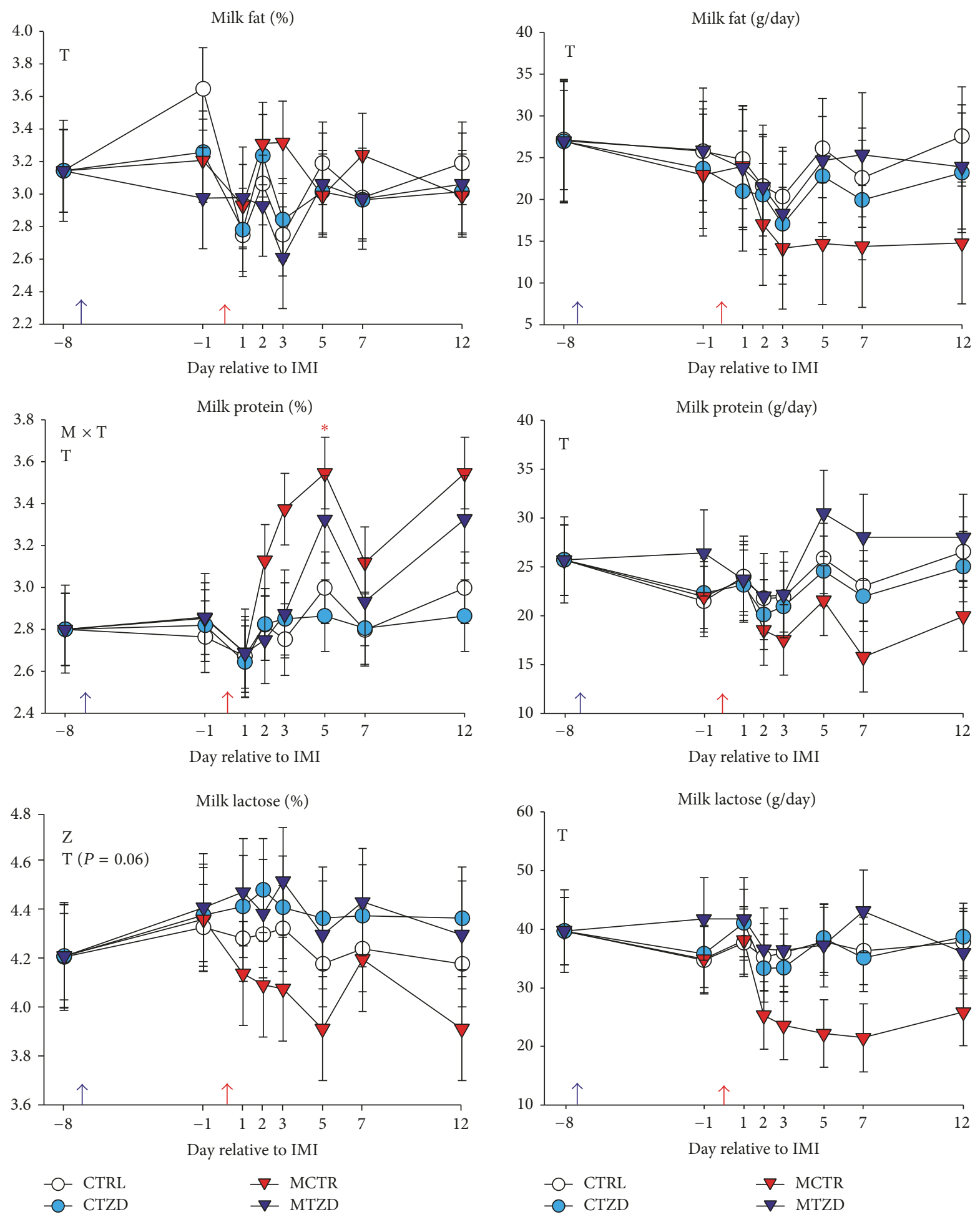

Figure 4: Milk components from -8 to $12 \mathrm{~d}$ relative to intramammary infusion of Strep. uberis (M) or saline in goats receiving daily intrajugular injection of 2,4-thiazolidinedione (TZD) or saline (CTR). Significant $(P \leq 0.05)$ effects and interactions are indicated in the graph (mastitis: M, time: T, and TZD: Z). The $P$ value for tendency is reported. Significant effect of $\mathrm{M} \times \mathrm{T}$ is denoted with red asterisk. 

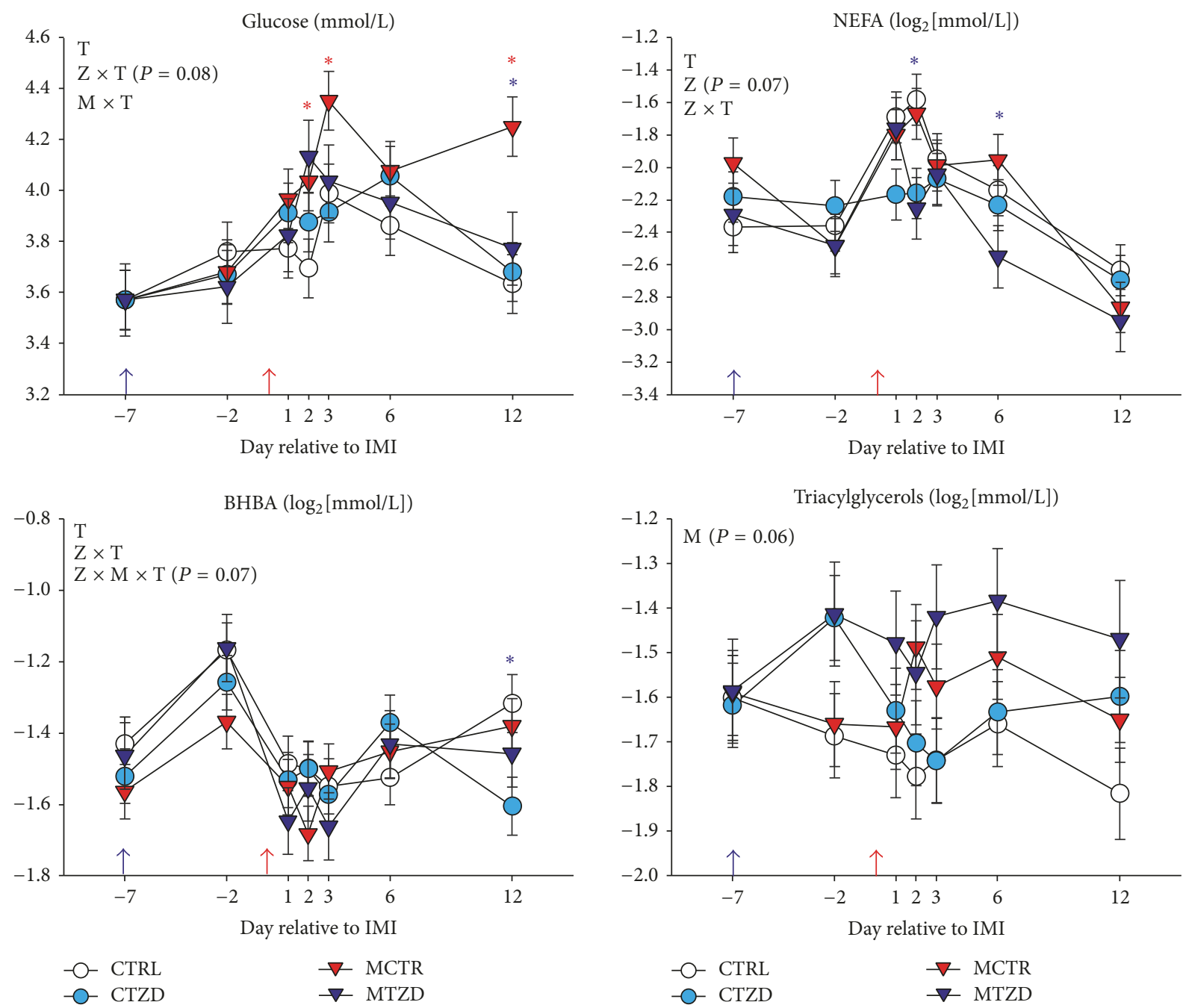

FIGURE 5: Plasma concentration of blood metabolic parameters from -7 to $12 \mathrm{~d}$ relative to intramammary infusion of Strep. uberis (M) or saline in goats receiving daily intrajugular injection of 2,4-thiazolidinedione (TZD) or saline (CTR). Significant $(P \leq 0.05)$ effects and interactions are indicated in the graph (mastitis: $\mathrm{M}$, time: T, and TZD: $Z$ ). The $P$ value for tendency is reported. Significant effect of $M \times T$ is denoted with red asterisk and effect of $\mathrm{Z} \times \mathrm{T}$ is denoted with purple asterisk.

RIN affected the RT-qPCR data. We performed correlation analysis between Cq and RIN. Contrary to the data reported in previous publications above cited, there was no overall significant inverse correlation between Cq values and RIN in all measured genes (Figure S10). Only the Cq values of FASN were negatively correlated with the RIN $(r=-0.23$; $P<0.05)$. This negative correlation was however balanced by the significant $(r=0.29 ; P<0.05)$ positive correlation between Cq and RIN in GAPDH (Figure S10). Therefore, the lack of correlation is indicative of the absence of effects of RNA degradation determined by RIN on RT-qPCR results in our experiment. These results can be partly explained by the very short sequence amplified by our primers (amplicon size around $100 \mathrm{bp}$, File S2) which might have prevented the effect of RNA degradation on Cq values. Due to the lack of correlation between RIN and Cq values, we deemed our RTqPCR results reliable.
Subcutaneous Adipose Tissue. Results for mRNA expression in adipose tissue are reported in Figure 9. The TNFA gene was undetectable in most of the samples so results are not shown. No effects were observed on expression of measured genes by mastitis or TZD treatment with exception of a $Z \times$ $\mathrm{M} \times \mathrm{T}$ interaction for SREBF1 due to a larger overall increase in expression of the gene in MTZD compared to the other groups after IMI.

Mammary Epithelial Cells. Results for the abundance of transcripts in mammary epithelial cells are reported in Figure 10. The expression of MUC1 was significantly affected by mastitis treatment, with a lower expression in mastitis-treated goats at $1 \mathrm{~d}$ after IMI, and a larger expression in TZD-treated versus control goats at $7 \mathrm{~d}$ after IMI. Mastitis induction significantly increased the expression of CCL2 after IMI. Expression of IL8 decreased over time in all groups but remained higher 

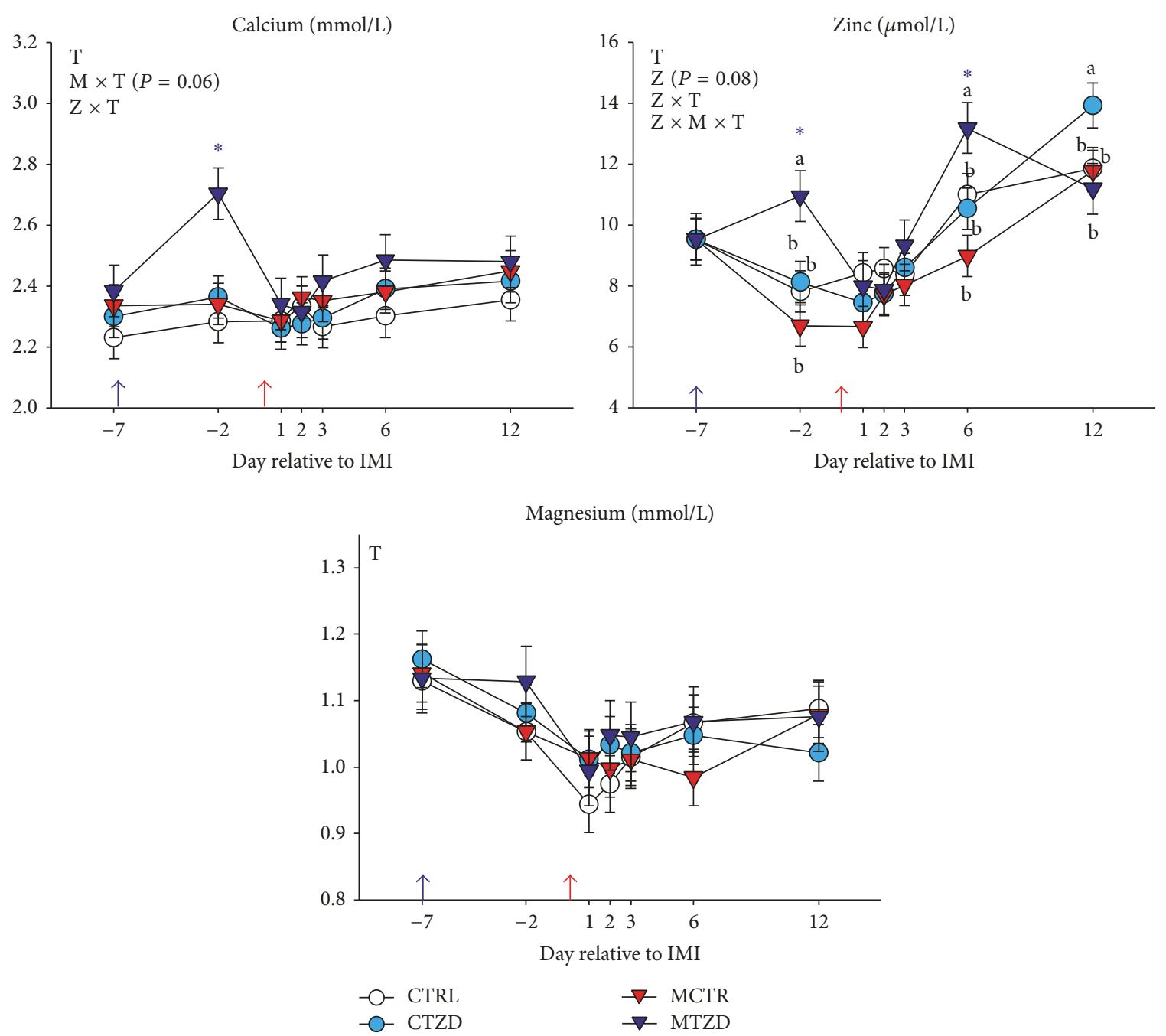

FiguRE 6: Plasma concentration of blood minerals from -7 to $12 \mathrm{~d}$ relative to intramammary infusion of Strep. uberis (M) or saline in goats receiving daily intrajugular injection of 2,4-thiazolidinedione (TZD) or saline (CTR). Significant $(P \leq 0.05)$ effects and interactions are indicated in the graph (mastitis: $\mathrm{M}$, time: T, and TZD: $\mathrm{Z}$ ). The $P$ value for tendency is reported. Significant effect $\mathrm{Z} \times \mathrm{T}$ is denoted with purple asterisk.

in goats treated with Strep. uberis the day after IMI. The transcript expression of PPAR $\gamma$ and its target genes SCD1, $F A S N$, and $L P L$ all increased or tended to increase through time. TZD-treated goats tended $(P=0.08)$ to have a higher expression of PPARG especially at $1 \mathrm{~d}$ after IMI. The expression of SCD1 tended to be higher in TZD-treated goats after IMI. The expression of FASN was negatively affected by mastitis, whereas TZD treatment prevented a decrease in expression of FASN but delayed the increase in expression of $L P L$ in mastitis-treated goats after IMI.

3.8. Size of Adipocytes. The average area of adipocytes was significantly increased over time and was affected by $\mathrm{M} \times \mathrm{Z} \times$ T because the CTZD group had a larger increase of adipocyte size after IMI compared to any other group (Figure 11). The frequency of adipocytes with medium areas (3,000 to $5,000 \mu \mathrm{m}^{2}$ ) was overall lower in TZD versus control goats at 1 day prior to IMI (i.e., 6 days of TZD treatment) and a decrease frequency of small adipocytes $\left(1,500\right.$ to $\left.3,000 \mu \mathrm{m}^{2}\right)$ was more pronounced in TZD-treated goats versus control at 7 days after IMI (Figures 12 and S11). When the diameter of adipocytes was considered (Figures S12 and S13), a lower frequency of medium-size adipocytes (60 to $80 \mu \mathrm{m})$ at $-1 \mathrm{~d}$ relative to IMI was evidenced for TZD versus control animals and a tendency for a higher frequency of large adipocytes $(>100 \mu \mathrm{m})$ was observed for TZD versus control animals, especially due to CTZD animals.

\section{Discussion}

4.1. The Subclinical Mastitis Model Used Works. In the present study all the animals receiving intramammary infusion with Strep. uberis developed subclinical mastitis. This was evidenced by the large increase in SCC $24 \mathrm{~h}$ after IMI without visible abnormalities in milk. Further support for subclinical mastitis was provided by the significant (although modest) 

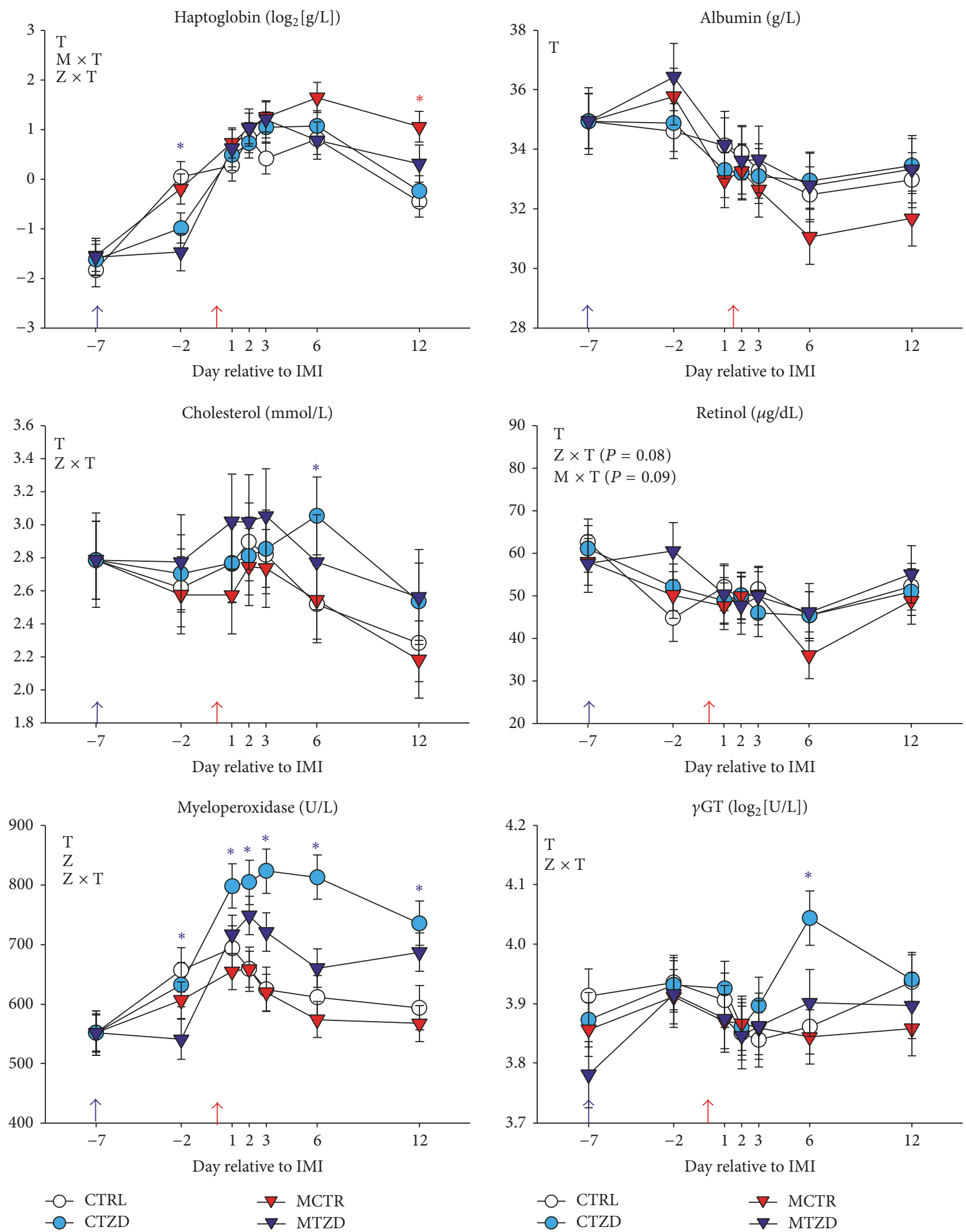

FIGURE 7: Plasma concentration of blood inflammatory markers and liver stress, including the positive acute phase protein haptoglobin, the markers of negative acute phase albumin, total cholesterol, and retinol, the neutrophils killing capacity marker myeloperoxidase, and the marker of liver stress/disease gamma-glutamyl transferase ( $\gamma \mathrm{GT})$ from -7 to $12 \mathrm{~d}$ of Strep. uberis (M) or saline intramammary infusion (IMI) in goats receiving daily intrajugular injection of 2,4-thiazolidinedione (TZD) or saline (CTR). Significant $(P \leq 0.05)$ effects and interactions are indicated in the graph (mastitis: $\mathrm{M}$, time: T, and TZD: $Z$ ). The $P$ value for tendency is reported. Significant effect of $M \times T$ is denoted with red asterisk and effect of $Z \times T$ is denoted with purple asterisk. 


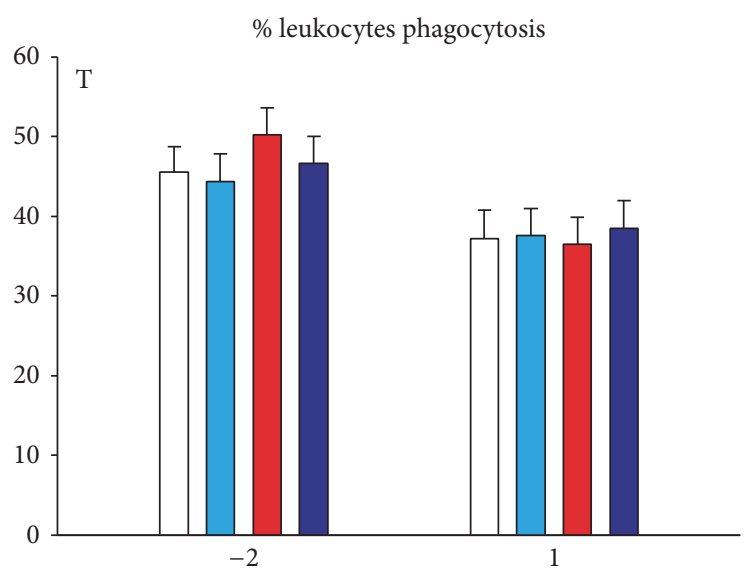

Day relative to IMI

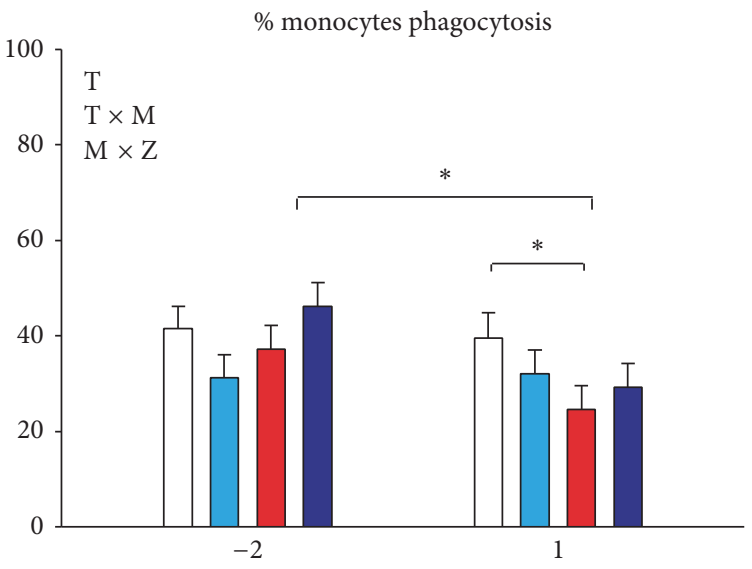

Day relative to IMI

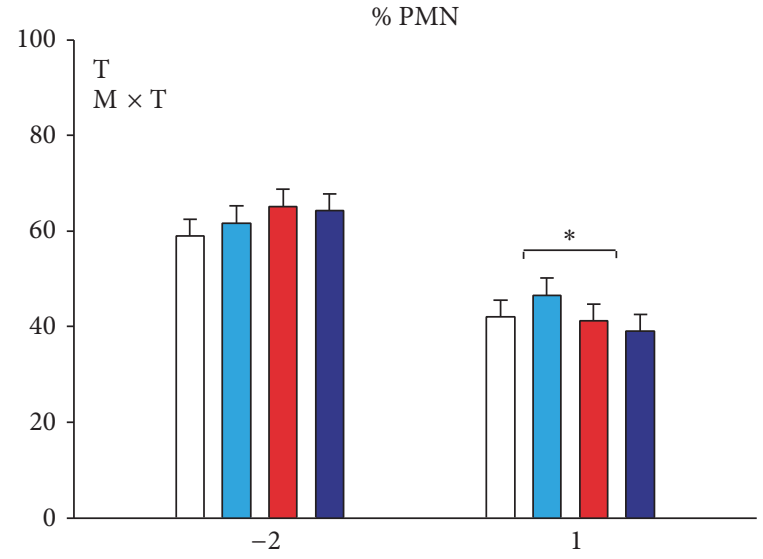

Day relative to IMI

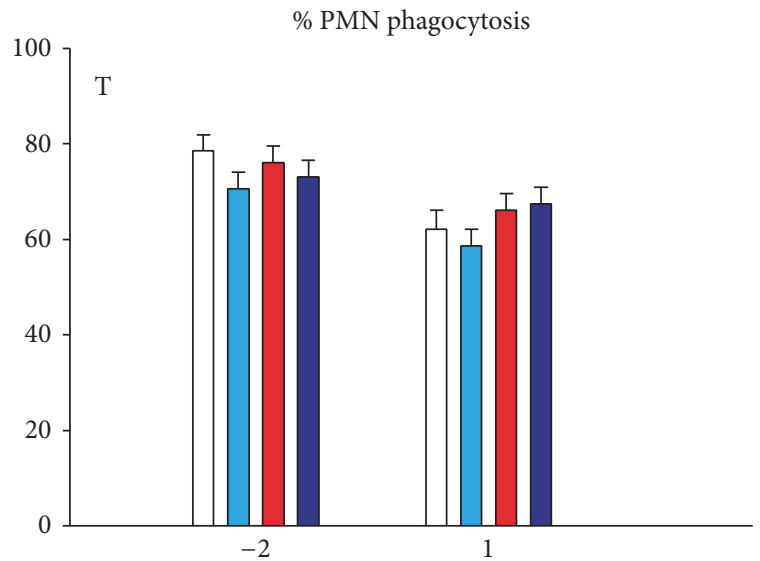

Day relative to IMI

Figure 8: Percentage phagocytosis in leukocytes, polymorphonuclear cells (PMN), and monocytes, and \% PMN on all leukocytes in goats receiving intramammary infusion (IMI) of Strep. uberis (M) or saline plus daily intrajugular injection of 2,4-thiazolidinedione (TZD) or saline (CTR). Significant $(P \leq 0.05)$ effects and interactions are indicated in the graph (mastitis: M, time: T, and TZD: $Z$ ). The $P$ value for tendency is reported. Significant differences $(P<0.05)$ are denoted by $*$.

higher rectal temperature between 12 and $44 \mathrm{~h}$ after IMI compared to control groups, by the decrease in milk yield, by the increase in expression of CCL2 in MEC, and by a significant decrease in \% PMN in blood within $24 \mathrm{~h}$ after IMI, likely caused by a temporary massive migration of neutrophils into the mammary gland. The CCL2 is a chemoattractant for neutrophils and macrophages [47] and crucial for the MECmacrophages crosstalk [48] and detected to be upregulated in cows receiving IMI with Strep. uberis [27]. During inflammatory episodes such as mastitis, plasma concentrations of acute phase proteins such as haptoglobin and ceruloplasmin are likely to increase. Indeed, in the present study all groups had an increase in plasma haptoglobin, indicating that all animals were experiencing some sort of inflammatory conditions. The mean level of haptoglobin before IMI in the goats used in the present experiment (i.e., $0.3 \mathrm{~g} / \mathrm{L}$ ) was higher than what was normally observed in healthy cattle $(<0.2 \mathrm{~g} / \mathrm{L})[33$, 49-52] and higher than what was previously observed in healthy goats $[53,54]$. A level that is considered high (or animals having a significant acute phase reaction) is when haptoglobin $>0.3 \mathrm{~g} / \mathrm{L}$; thus, our animals had some basal level of inflammation. In our experiment, haptoglobin was higher than $0.3 \mathrm{~g} / \mathrm{L}$ after IMI in all groups and the concentration in plasma of indexes of negative acute phase reaction such as albumin, paraoxonase, total cholesterol, and retinol was decreased, indicating a significant inflammatory state after IMI [49, 51].

Our data confirmed the reliability of the model developed by Lasagno and collaborators [31] that used the same dose of Strep. uberis to induce subclinical mastitis in lactating goats. Furthermore, data are indicative of basal inflammatory conditions in the goats used in the present experiment. Positive acute phase proteins are known to be affected by transport and commingling in weaned calves [55]. It might be possible that when we started the experiment (1 week after transport and commingling) the animals were still experiencing some stress and/or inflammatory conditions that have induced slight acute phase response.

4.2. Metabolic and Inflammatory Response to Induced Intramammary Infection. Goats receiving intramammary Strep. uberis had an increase in plasma glucose and NEFA and 

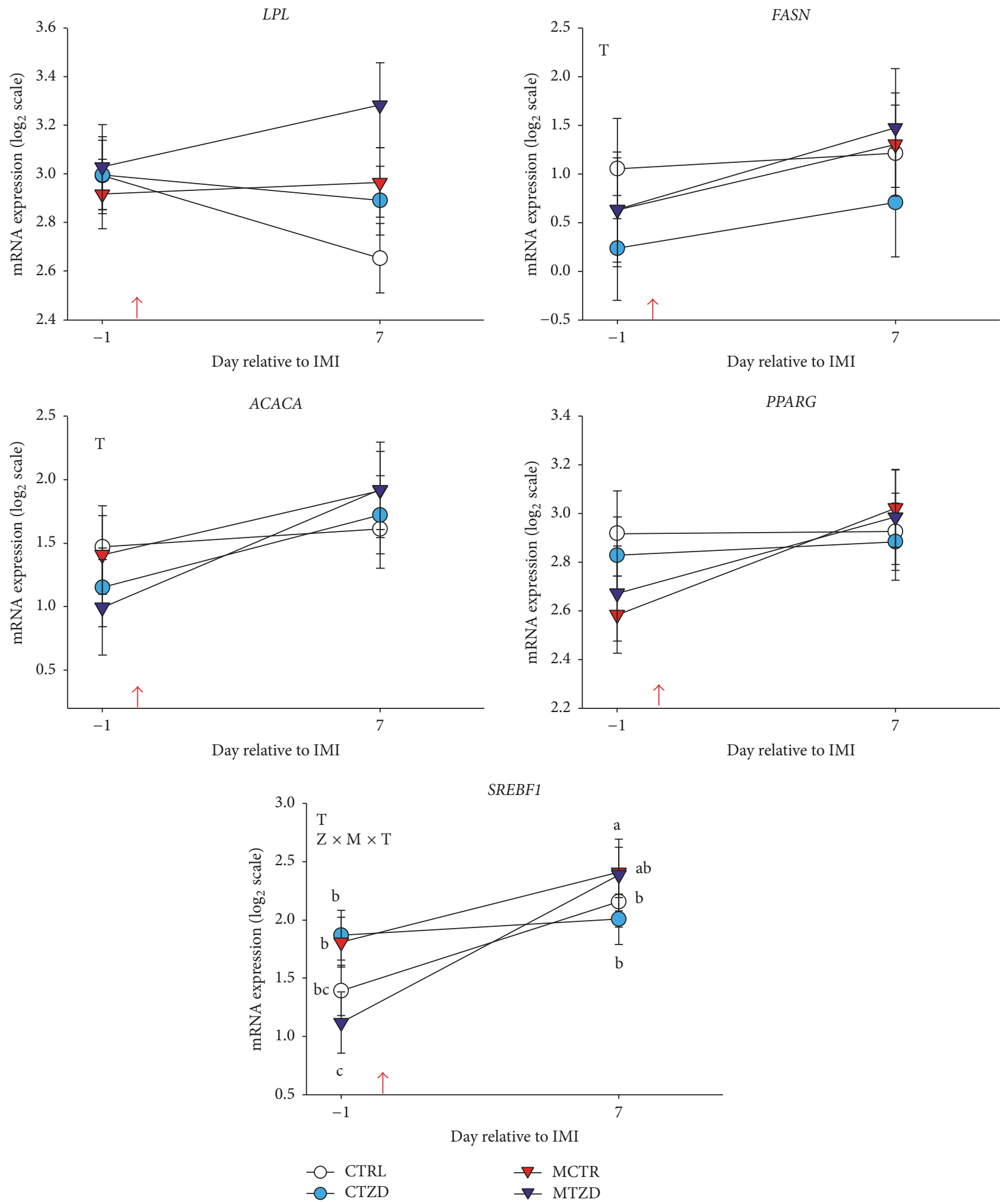

FIGURE 9: Transcript abundance of selected genes in subcutaneous adipose tissue in goats receiving intramammary infusion (IMI) of Strep. uberis $(\mathrm{M})$ or saline plus daily intrajugular injection of 2,4-thiazolidinedione (TZD) or saline (CTR). Significant $(P \leq 0.05)$ effects and interactions are indicated in the graph (mastitis: $\mathrm{M}$, time: T, and TZD: $\mathrm{Z}$ ). 

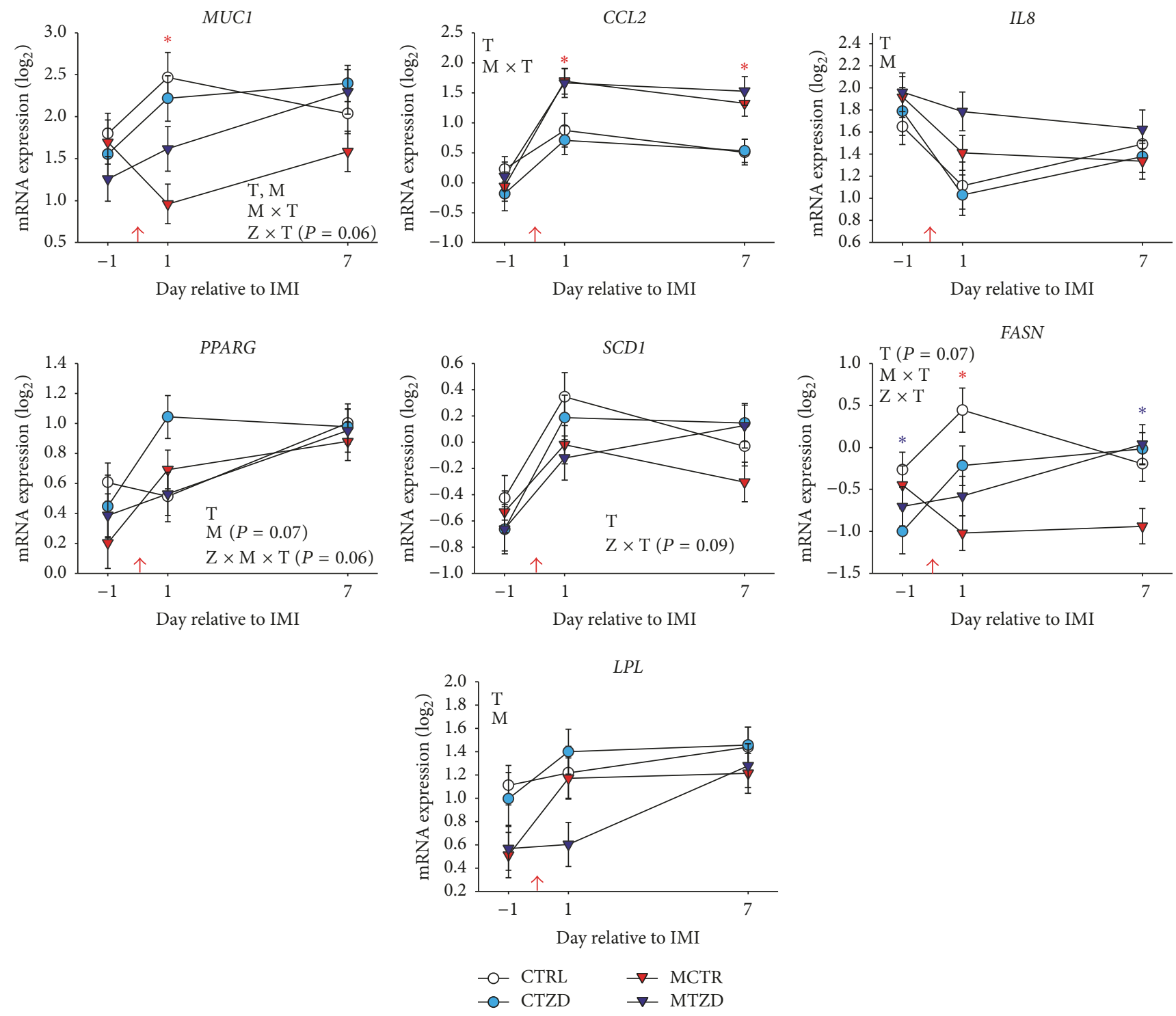

FIGURE 10: Transcript abundance of selected genes in mammary epithelial cells in goats receiving intramammary infusion (IMI) of Strep. uberis $(\mathrm{M})$ or saline plus daily intrajugular injection of 2,4-thiazolidinedione (TZD) or saline (CTR). Significant $(P \leq 0.05)$ effects and interactions are indicated in the graph (mastitis: M, time: T, and TZD: Z). Significant differences due to mastitis $\times$ time $(M \times T)$ and TZD $\times$ time $(\mathrm{Z} \times \mathrm{T})$ are denoted with red asterisk and purple asterisk, respectively.

decrease in BHBA concentrations after IMI. The pattern of these parameters is consistent with the data reported in a study where induction of mastitis was obtained using the gram negative bacteria E. coli in primiparous Holstein dairy cows [56]. Our data are somewhat consistent with the increase in NEFA and glucose in plasma in fedrestricted multiparous dairy cows receiving intramammary Strep. uberis, although the increase in NEFA was observed by $12 \mathrm{~h}$ but not at $36 \mathrm{~h}$ after IMI in that study [57]. In our study the increase in NEFA was also observed in CTRL group, which did not receive intramammary Strep. uberis but had a larger rectal temperature compared to CTZD at $12 \mathrm{~h}$ and $44 \mathrm{~h}$ after IMI. The same group appeared to have had an increase in SCC prior to IMI and had a slightly larger proinflammatory response compared to TZD-treated group. The CTRL group also appeared to have had a similar pattern as the MCTR group for several inflammatory-related parameters, such as albumin, cholesterol, myeloperoxidase, and NEFA, despite not having a significant increase in SCC. On examination of the inflammatory-related parameters, it is apparent that all the animals had an inflammatory response as indicated by a general increase in haptoglobin, ceruloplasmin, and total ROM and a general decrease in magnesium, albumin, cholesterol, and paraoxonase, all markers of inflammatorylike conditions [33, 49,58]. The change in inflammatory markers was, however, not accompanied by a significant increase in SCC in goats receiving saline in the mammary. The increase in inflammation in goats not receiving Strep. uberis could have been partly due to the injection of saline in both halves of the mammary. However physiological saline 


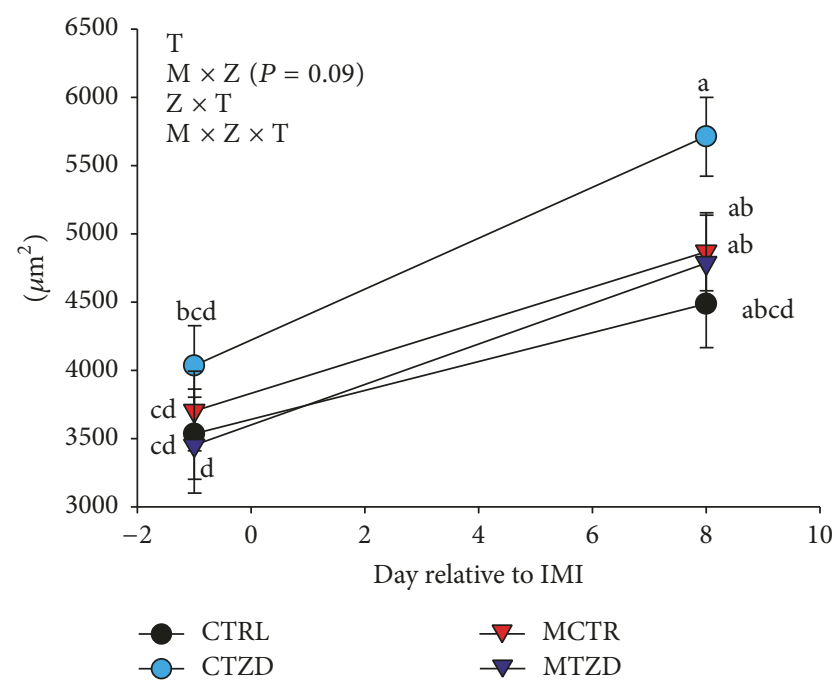

FIGURE 11: Area of adipocytes in subcutaneous adipose tissue collected from the tail-head of goats receiving intramammary infusion (IMI) of Strep. uberis (M) or saline plus daily intrajugular injection of 2,4-thiazolidinedione (TZD) or saline (CTR). Significant $(P \leq 0.05)$ effects and interactions are indicated in the graph (mastitis: $M$, time: T, and TZD: Z). Significant differences $(P<0.05)$ between time point are denoted by diverse letters.

is known to be relatively innocuous when injected into bovine mammary [59] but stress induced by capturing the animals and frequent injections and samplings can be partly responsible for the observed apparent inflammatory response [60].

Contrary to our findings, there was no decrease in BHBA in the study from Moyes et al. [57] but our data were more similar to the data reported by Graugnard et al. [61], in which IMI with endotoxin was performed in dairy cows. In our study the decrease in BHBA after IMI was observed in all animals, which might be indicative of either an overall response to inflammation (see above) or a metabolic change in all animals unrelated to IMI, likely due to a reduction of the feed intake which reduce the component of BHBA from the rumen fermentation [62]. The increase in glucose in our study can be associated with the decrease in milk yield and, especially, lactose yield, as demonstrated by Moyes and collaborators [56]. All the above observations are indicative of a similar metabolic response among cows and goats to IMI using Strep. uberis.

\subsection{Higher TG, NEFA, and Glucose in Blood Might Indicate} an Effect on Insulin Sensitivity by Mastitis. In the study by Moyes and collaborators [57], the cows feed-restricted had an increase in TG after IMI, similar to the tendency we observed in our study. The increase in TG after IMI is not explained by the decrease in uptake of fat by the mammary gland, because a decrease in milk fat synthesis, although only numerically, was observed only for MCTR group, nor can it be explained by a very unlikely increase in feed intake or larger NEFA, which was also present in CTRL group that did not experience an increase in TG after IMI. An increase in TG in blood can be caused by insulin resistance [63]; however, the insulin sensitivity indexes did not indicate a significantly greater insulin resistance in goats receiving Strep. uberis. Recently, it was argued and somewhat demonstrated in dairy cows that the insulin indexes used in the present study are probably not a good indicator of true insulin sensitivity [64] and a glucose clamp is likely necessary to accurately measure insulin sensitivity. Therefore, it remains possible that, despite the lack of any indication of insulin resistance by the insulin sensitivity indexes, goats with IMI experienced some decrease in insulin sensitivity.

The increase in glucose and NEFA after IMI observed in our and other studies can be associated with the inflammatory response. The proinflammatory cytokine $\mathrm{TNF} \alpha$ is known to induce temporary insulin resistance in monogastrics [65]. The work from Kushibiki and collaborators [66] demonstrated that this effect is conserved in ruminants; however, a more recent study by Yuan and collaborators [67] did not demonstrate any effect of TNF $\alpha$ injection on glucose, NEFA, or insulin in early lactation dairy cows. In our case, we detected an increase in glucose and NEFA during the first $2 \mathrm{~d}$ after IMI but at $3 \mathrm{~d}$ after IMI NEFA returned to the value prior to IMI. Similarly, insulin $3 \mathrm{~d}$ after IMI was similar to before IMI. The measurement of insulin at $3 \mathrm{~d}$ after IMI might have missed the temporary insulin resistance. Somewhat similar to our data, Moyes and collaborators [57] did not find any effect on insulin level in blood after IMI in feed-restricted animals. Interestingly, the same authors detected a large increase in blood insulin after IMI in cows having a positive energy balance. Overall, our data do not allow concluding about the effect of IMI of Strep. uberis on insulin sensitivity but the response appears similar to feed-restricted animals.

4.4. Response to Mastitis Is Affected by Precondition of the Animals. The observed increase in NEFA after IMI could be a response to lower feed intake, as high plasma NEFA concentrations are indicative of negative energy balance [68]. We did not measure feed intake, but none of the other data, including body weight and BHBA, are indicative of a significant and/or prolonged reduction of feed intake. In addition, the goats were producing a relatively small amount of milk (approx. $1 \mathrm{~kg} / \mathrm{d}$ ), the adipocyte size increased over time, and they were in late lactation; thus, a negative energy balance, if present, was temporary and of little importance. However, as discussed above, the response to mastitis in the present study is somewhat similar to dairy cows in negative energy balance in the study of Moyes et al. [57] and the body condition score of the goats in our study was $1.6 \pm 0.5$ (mean $\pm \mathrm{SD}$; scale 1-5), which is in the low range compared to the values reported in literature for this breed of goats and stage of lactation [69]. In our experiment, the ration was not optimized for lactating goats. This was done with the purpose of being consistent with the diet originally provided by the commercial farm where the goats were purchased. The diet may have not been adequate, as suggested by a response to mastitis more similar to animals in negative energy balance, indicating a possible nutritional deficiency. The possible deficiency could have been partly determined also by the original condition of the animals indicated by the less than optimal body condition and the relatively high acute phase 

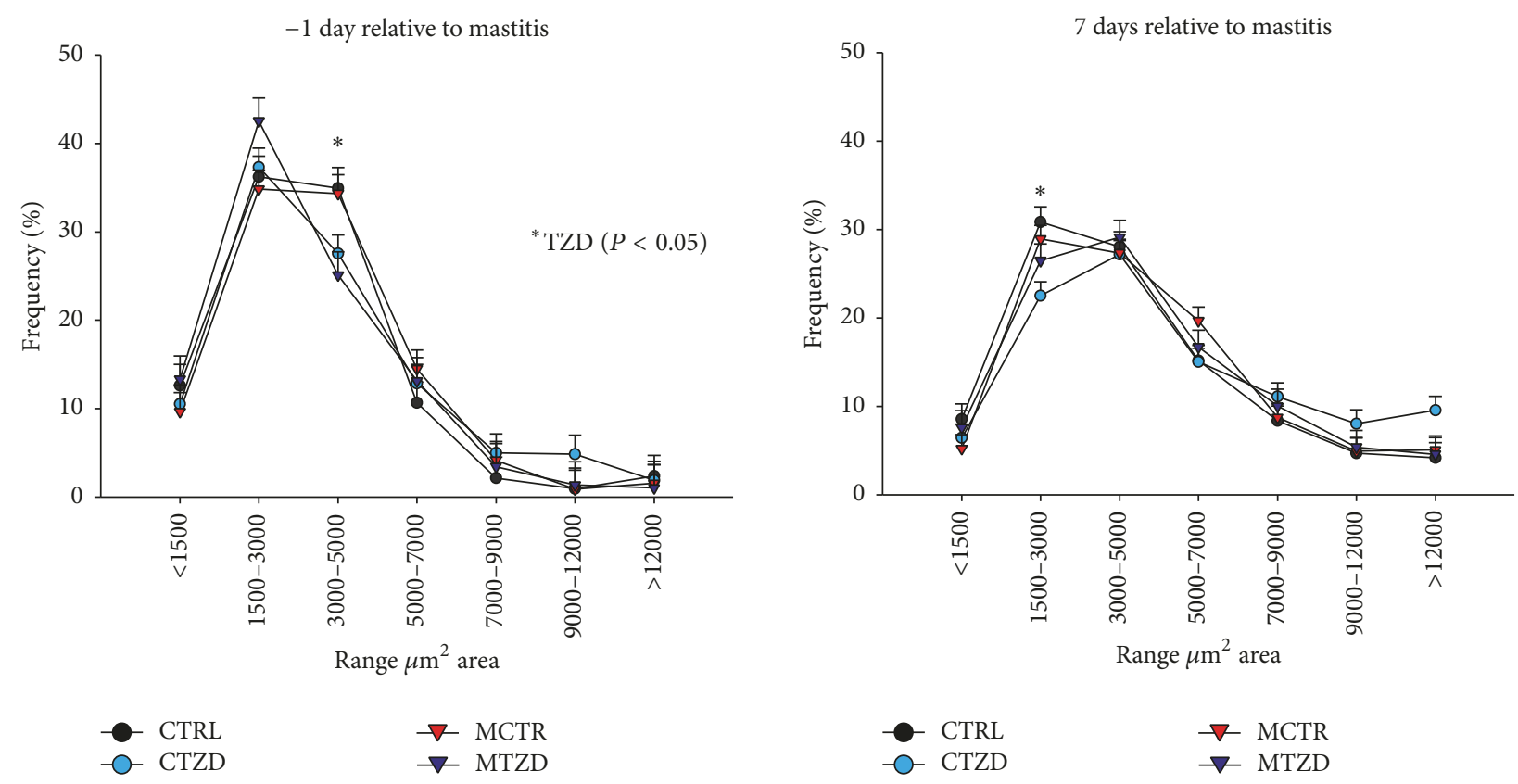

FIGURE 12: Frequency of adipocytes in subcutaneous adipose tissue collected from the tail-head of goats receiving intramammary infusion (IMI) of Strep. uberis (M) or saline plus daily intrajugular injection of 2,4-thiazolidinedione (TZD) or saline (CTR). Significant difference due to TZD is indicated by $*$.

that could have influenced the response to intramammary infection.

4.5. Effect of TZD Treatment: General Aspects. 2,4-Thiazolidinedione is the basic molecular compound for the chemical synthesis of all thiazolidinedione molecules known to be specific and potent PPAR $\gamma$ agonists, including rosiglitazone and pioglitazone [70, 71]. Because of this, 2,4-thiazolidinedione was assumed to be a PPAR $\gamma$ agonist; however, to our knowledge, it has not been proved that 2,4-TZD is a PPAR $\gamma$ agonist. Indirect support for this compound being a PPAR $\gamma$ agonist is coming from prior studies in ruminants. In heifers and dairy cows it was demonstrated that 2,4-thiazolidinedione injection counteracted the insulin resistance after $\mathrm{TNF} \alpha$ injection [66] and significantly decreased NEFA post-partum in dairy cows [72], respectively. Based on the above evidence, we assumed, in the present study, that 2,4-TZD is a PPAR $\gamma$ agonist.

4.6. Larger Adipocytes Size May Indicate Large Insulin Sensitivity in TZD-Treated Animals. The prevention of insulin resistance in heifers treated with $\mathrm{TNF} \alpha$ was achieved by treatment with TZD by Kushibiki and collaborators [66]. We did not observe any significant effect of TZD on insulin sensitivity indexes, with only numerically greater QUICKI compared to control animals prior to IMI. Lack of effect on insulin sensitivity indexes in our study is in accordance with data in dairy cows from Schoenberg and Overton [73], where the TZD was used before birth, and Yousefi and collaborators [74], where pioglitazone, another thiazolidinedione and a well-established synthetic PPAR $\gamma$ ligand, was used during the entire transition period.
As stated above, the insulin sensitivity indexes used may not apply to ruminants. The larger increase in adipocyte size accompanied by a lower NEFA in CTZD animals after IMI compared to the other groups can indicate an improved insulin sensitivity by TZD. An increase in adipocyte size is consequence of TG accumulation. Adipose tissue accumulates TG under the influence of insulin; thus, the data appear to indicate that adipose tissue in CTZD group had greater insulin sensitivity compared to the other groups. However, we are unable without an insulin or glucose clamp to provide a definitive conclusion about insulin sensitivity in this study.

4.7. TZD Treatment Helped to Maintain Milk Yield and Milk Fat Production after IMI. Milk yield was not affected by TZD in normal goats but TZD treatment prevented the decrease of milk yield after IMI with Strep. uberis. Administration of TZD during the present trial did not significantly affect milk composition but, as with milk yield, milk fat and lactose were not decreased in MTZD as much as with MCTR. A direct effect of TZD on prevention of milk fat synthesis decline can be inferred by the higher expression in MEC of FASN in MTZD versus MCTR at $7 \mathrm{~d}$ after IMI and a numerically higher expression of SCD at the same time point. The higher expression of FASN and the lower expression of $L P L$ in MTZD versus MCTR may indicate a different effect of TZD on de novo versus preformed fatty acids in milk after IMI [17]. Interestingly, milk fat depression is characterized by a larger decrease in expression of FASN compared to $L P L$ [75]. It has been previously observed in vitro that expression of FASN, but not $L P L$, is increased upon activation of PPAR $\gamma$ by rosiglitazone [18]. The response of FASN to rosiglitazone appears to be consistent among ruminants, as 
recently reviewed [13]. Overall, those data might indicate some activation of PPAR $\gamma$ in MEC by 2,4-thiazolidinedione.

\begin{abstract}
4.8. TZD Treatment Prevented a Large Acute Phase Reaction and Improved Liver Response to IMI. The larger increase of haptoglobin in non-TZD- versus TZD-treated goats before IMI and after IMI, particularly in MCTR goats, and the higher level of total plasma cholesterol in TZD versus control goats are suggestive of improved liver activity by TZD [34, 51]. A better liver status in TZD-treated versus control animals is also supported by the tendency for a higher $\mathrm{Zn}$ level in blood [76]. Taking these findings together, there is an indication that the animals treated with TZD had a lower inflammatory status before IMI but, after IMI, the same animals had a faster recovery of the inflammatory status due to a better response by the liver. Thus, the TZD treatment appears to have improved the response to mastitis.
\end{abstract}

4.9. TZD Increased Killing Capacity of Neutrophils. Recruitment and activation of neutrophils is known to be a principal defense mechanism of innate immunity. In addition, during inflammation, neutrophils are the major cell type observed in the mammary gland [77]; thus, their ability to migrate to the site of infection plays a critical role in the inflammatory response. In the present study, the decrease in the \% of blood PMN phagocytosis in plasma $1 \mathrm{~d}$ after the IMI and the concomitant increase in SCC are suggestive of a chemotactic process of the mammary toward neutrophils in all groups but larger in goats receiving Strep. uberis, also supported by higher IL8 expression in MEC of goats treated with Strep. uberis compared to control groups after IMI. Although no difference in phagocytosis of blood PMN was detected between groups, the larger increase in MPO is indicative of a larger microbial killing capacity in TZD-treated versus control goats [78]. Neutrophil granulocytes have a high abundance of the enzyme MPO, constituting the majority of azurophilic granules. The MPO produces the antimicrobial compound hypohalous acid, which can be released into circulation but it is also pivotal for bacteria killing after phagocytosis $[78,79]$. The increase in blood MPO can be due to an increase in neutrophil count [80] and/or by an increase of MPO expression by neutrophils. It has been demonstrated that PPAR $\gamma$ controls MPO expression in certain activated macrophages [81] but rosiglitazone decreased MPO content of neutrophils in rabbits [82] and pioglitazone decreased both number of neutrophils and expression of MPO in several species [83]. In our study it is likely that TZD increased the expression of MPO. It is not possible to conclude this with certainty in the present study because we did not perform a whole blood leukocyte count; however, the lack of difference of \% PMN between groups supports an increase in release and/or expression of MPO by neutrophils in the TZD group. Higher MPO has been also associated with greater inflammation [84]. Inflammatory markers did not indicate increased inflammation but rather attenuated inflammation in TZD-treated versus control goats; thus, it is more likely that the expression of MPO was increased by TZD. Overall, our data indicate that, despite TZD not having an effect on PMN phagocytosis, the bacteria killing capacity of the neutrophils was likely augmented.

4.10. TZD Increased Adipocytes Size Despite Not Having Transcriptomic Effects. Data indicated an effect of TZD on adipose tissue by decreasing the release of NEFA and slightly changing the adipocyte size profile. The histological data indicated that TZD-treated goats had a significant decrease in medium-size adipocytes after 1 week of TZD treatment. An increase of small adipocytes is indicative of active adipogenesis. The formation of new adipocytes generally precedes the formation of large adipocytes [85]. Our data are consistent with this general observation because the proportion of large adipocytes was larger in TZD-treated animals in later stages. PPAR $\gamma$ is a well-established master regulator of adipogenesis [15]. Therefore, it appears that TZD had a biological effect on adipose tissue. Surprisingly, no TZD effect was observed in the expression of target genes in adipose tissue. Lack of effect on expression of genes in adipose tissue is consistent with a study conducted in pregnant dry dairy cows [73]. However, in another study where nonpregnant dry cows were used, the injection of TZD affected the expression of several genes, including PPAR $\gamma$ target genes, but the effect was only temporary despite continuous injection [86].

Despite the absence of a significant effect on expression of several of the main lipogenic genes in adipose tissue, the presence of lower NEFA and larger adipocytes, especially in CTZD group, is indicative of lipid accumulation. An accumulation of triglycerides in adipose tissue can compete for lipid precursors with the mammary gland. This cannot be fully proven in the present work but we can speculate that, if existing, we should have detected a decrease in milk fat production in CTZD animals. We did not observe significant changes in milk fat. However, we did observe a tendency for higher expression in MEC of several lipogenic genes and targets of PPAR $\gamma$ such as FASN, SCD1, and PPARG in CTZDtreated animals [13]. Therefore, we can speculate that TZD in our experiment helped the mammary tissue to maintain milk fat synthesis despite the competition with adipose tissue for fatty acids.

4.11. Was the Response to TZD Impaired by Less Than Optimal Body Condition and Dietary Deficiency? The lack of effect of TZD on expression of PPAR $\gamma$ target genes in adipose tissue and the very small effect on expression of the same genes in MEC are indicative of TZD being a weak activator of PPAR $\gamma$. However, recent in vitro work performed in bovine mammary cells indicated that in order for 2,4-thiazolidinedione to activate PPAR $\gamma$ the vitamin A metabolite 9-cis-retinoic acid is required [11]. The 9-cis-retinoic acid is a specific activator of Retinoic-X-Receptor, the obligate heterodimer of PPAR $\gamma$ [13]. As discussed above, the goats in the present experiment appeared to have a response to Strep. uberis similar to cows in negative energy balance. Our goats were thin and they came from a farm where they never grazed and received only hay and a small amount of supplement. This feeding regime probably provided an insufficient amount of retinol. It is therefore possible that our goats had some deficiency in vitamin A and, thus, a lower level of 9-cis-retinoic acid 
reducing the response to $\operatorname{PAAR} \gamma$ activator. Unfortunately, we did not measure level of 9-cis-retinoic acid in plasma in the present experiment.

\section{Limitations and Opportunities of the Study}

The present study presents several limitations. These include the availability of goats with a body condition which was less than optimal and lack of a balanced ration for lactating goats both prior to and during the experiment. Furthermore, we did not measure individual feed intake. The above limitations can be however considered also an opportunity. Dairy cows, in general, experience negative energy balance and deficiency of various nutritional compounds in early postpartum period. This is also the time of higher incidence of mastitis; thus, our model appears to be more relevant for early rather than late lactating cows. The inferred possible deficiency (or low level) of 9-cis-retinoic acid in blood could have decreased the response of PPAR $\gamma$ to TZD. For the above reasons, a future experiment considering the same treatment in animals with good body condition and well-fed, including adequate level of vitamin $\mathrm{A}$, should be performed.

The interpretation of the large increase in myeloperoxidase would have been easier with the white blood cell count data. The use of insulin and various insulin sensitivity indexes does not appear to be adequate; the use of an insulinaemic clamp could have aided in data interpretation. The low RIN of our total RNA is less than ideal. Despite this we demonstrated that the low RIN is not always a problem and data can be used if a lack of effect of the RIN on gene expression is demonstrated.

Finally, the study would have benefitted from the use of a larger number of animals. Six animals can provide enough statistical power but, as was in our case, the loss of 2 animals had likely reduced the capability of observing biologically relevant effects.

\section{Summary and Conclusions}

The subclinical mastitis model used in the present experiment was previously established. Here we have confirmed the validity of this model and it can be used for future studies. Furthermore, the response of the goats to intramammary infusion of Strep. uberis is somewhat similar to dairy cows experiencing negative energy balance.

Administration of TZD to lactating dairy goats undergoing subclinical mastitis had a relatively modest effect on milk yield and components and on overall metabolism with a possible temporary decrease on insulin sensitivity which was improved by TZD treatment. The TZD injection had a strong effect on the inflammatory response and SCC. Especially noteworthy was the effect of TZD on the liver, with a better overall response to the inflammatory situation after IMI, and on neutrophils functions. Despite not having any effect on leukocyte phagocytosis, TZD increased the killing capacity of neutrophils (i.e., myeloperoxidase). Overall the data indicated that the animals treated with TZD had an improved organismal response to the mammary infection.

The milk fat synthesis was not increased but the decline of milk fat synthesis due to mammary infection was partially attenuated by TZD treatment. Although we detected some biological effects of TZD injection, we did only observe a modest effect on expression of PPAR $\gamma$ target genes in MEC but not effects on adipose tissue. The less than expected response on gene expression is indicative of TZD being a relatively weak activator of PPAR $\gamma$. It is also possible that, in the present study, the lack of a transcriptomic effect of TZD was due to the less than adequate conditions of the animals and/or some sort of nutritional deficiency. We speculate that the goats in the present experiment had a less than adequate amount of vitamin A and of its metabolite 9-cis-retinoic acid. This speculation deserves further investigations.

Our hypotheses were that activation of PPAR $\gamma$ (1) improves the response to mammary infection and (2) augments synthesis of milk fat. We can conclude that TZD injection improved the overall response to mammary infection with no or minimal effect on milk synthesis and gene expression. Our data indicate the possibility that $\operatorname{PAAR} \gamma$ was only weakly activated by TZD, impeding a full demonstration of the above hypotheses. In order to fully prove the above hypotheses a study using an adequate diet in goats with a good body condition is required.

\section{Conflicts of Interest}

The authors declare that they have no conflicts of interest.

\section{Acknowledgments}

The work presented was supported by the Hatch/Multistate USDA Animal Health and Disease Grant no. NE1048 received by Massimo Bionaz and Charles T. Estill from the Oregon State University research station. The authors thank Mary Smallman and the OSU Sheep Center staff for help with animal management. Appreciation is extended to Professor Joseph S. Beckman (Department of Biochemistry and Biophysics at Oregon State University) and Nathan Lopez (Faculty Research Assistant at Beckman's Lab, Department of Biochemistry and Biophysics at Oregon State University) for help with the cryostat and staining methods. The authors thank Samantha Richards, Lauren Robertson, Danita Dahl, and Laura Johnston for the essential help in carrying out the in vivo experiments, including taking care of the animals, milking, injecting 2,4-thiazolidinedione, and blood and milk samples collection. The authors thank Professor Gerd Bobe from the Animal and Rangeland Sciences Department at Oregon State University for critical revision of the paper.

\section{References}

[1] T. Halasa, K. Huijps, O. Østerås, and H. Hogeveen, "Economic effects of bovine mastitis and mastitis management: a review," Veterinary Quarterly, vol. 29, no. 1, pp. 18-31, 2007.

[2] H. Hogeveen, K. Huijps, and T. J. G. M. Lam, "Economic aspects of mastitis: new developments," New Zealand Veterinary Journal, vol. 59, no. 1, pp. 16-23, 2011.

[3] M. Awale, G. Dudhatra, K. Avinash, B. Chauhan, D. Kamani et al., "Bovine mastitis: a threat to economy," Open Access Scientific Reports, p. 295, 2012. 
[4] G. M. Jones, Understanding the Basics of Mastitis, Virginia Cooperative Extension, 2009.

[5] D. Bar, Y. T. Gröhn, G. Bennett et al., "Effect of repeated episodes of generic clinical mastitis on milk yield in dairy cows," Journal of Dairy Science, vol. 90, no. 10, pp. 4643-4653, 2007.

[6] A. J. Heinrichs, S. S. Costello, and C. M. Jones, "Control of heifer mastitis by nutrition," Veterinary Microbiology, vol. 134, no. 1-2, pp. 172-176, 2009.

[7] R. J. Erskine, "Nutrition and mastitis," Veterinary Clinics of North America: Food Animal Practice, vol. 9, no. 3, pp. 551-561, 1993.

[8] A. H. Lichtenstein, E. Kennedy, P. Barrier et al., "Dietary fat consumption and health," Nutrition Reviews, vol. 56, no. 5, pp. 3-19, 1998.

[9] M. Arévalo-Turrubiarte, L. González-Dávalos, A. Yabuta et al., "Effect of 2,4-thiazolidinedione on Limousin cattle growth and on muscle and adipose tissue metabolism," PPAR Research, Article ID 891841, 8 pages, 2012.

[10] G. Bertoni, A. Minuti, and E. Trevisi, "Immune system, inflammation and nutrition in dairy cattle," Animal Production Science, vol. 55, no. 7, pp. 943-948, 2015.

[11] M. Bionaz, J. Osorio, and J. J. Loor, “Triennial lactation symposium: nutrigenomics in dairy cows: nutrients, transcription factors, and techniques," Journal of Animal Science, vol. 93, no. 12, pp. 5531-5553, 2015.

[12] D. M. Mutch, W. Wahli, and G. Williamson, "Nutrigenomics and nutrigenetics: the emerging faces of nutrition," FASEB Journal, vol. 19, no. 12, pp. 1602-1616, 2005.

[13] M. Bionaz, S. Chen, M. J. Khan, and J. J. Loor, "Functional role of PPARs in ruminants: potential targets for fine-tuning metabolism during growth and lactation," PPAR Research, vol. 2013, Article ID 684159, 28 pages, 2013.

[14] B. Desvergne, L. Michalik, and W. Wahli, "Transcriptional regulation of metabolism," Physiological Reviews, vol. 86, no. 2, pp. 465-514, 2006.

[15] P. Tontonoz and B. M. Spiegelman, "Fat and beyond: the diverse biology of PPARy," Annual Review of Biochemistry, vol. 77, pp. 289-312, 2008.

[16] J. N. Feige, L. Gelman, L. Michalik, B. Desvergne, and W. Wahli, "From molecular action to physiological outputs: peroxisome proliferator-activated receptors are nuclear receptors at the crossroads of key cellular functions," Progress in Lipid Research, vol. 45, no. 2, pp. 120-159, 2006.

[17] M. Bionaz and J. J. Loor, "Gene networks driving bovine milk fat synthesis during the lactation cycle," BMC Genomics, vol. 9, no. 1, article 366, 2008.

[18] A. K. G. Kadegowda, M. Bionaz, L. S. Piperova, R. A. Erdman, and J. J. Loor, "Peroxisome proliferator-activated receptor- $\gamma$ activation and long-chain fatty acids alter lipogenic gene networks in bovine mammary epithelial cells to various extents," Journal of Dairy Science, vol. 92, no. 9, pp. 4276-4289, 2009.

[19] H. Shi, J. Luo, J. Zhu et al., "PPAR $\gamma$ regulates genes involved in triacylglycerol synthesis and secretion in mammary gland epithelial cells of dairy goats," PPAR Research, vol. 2013, Article ID 310948, 10 pages, 2013.

[20] J. Zhu, Y. Sun, J. Luo, M. Wu, J. Li, and Y. Cao, "Specificity protein 1 regulates gene expression related to fatty acid metabolism in goat mammary epithelial cells," International Journal of Molecular Sciences, vol. 16, no. 1, pp. 1806-1820, 2015.

[21] D. Vyas, B. B. Teter, P. Delmonte, and R. A. Erdman, "Rosiglitazone, a PPAR- $\gamma$ agonist, fails to attenuate CLA-induced milk fat depression and hepatic lipid accumulation in lactating mice," Lipids, vol. 49, no. 7, pp. 641-653, 2014.

[22] S. Mandard and D. Patsouris, "Nuclear control of the inflammatory response in mammals by peroxisome proliferator-activated receptors," PPAR Research, vol. 2013, Article ID 613864, 23 pages, 2013.

[23] T. Varga, Z. Czimmerer, and L. Nagy, "PPARs are a unique set of fatty acid regulated transcription factors controlling both lipid metabolism and inflammation," Biochimica et Biophysica Acta, vol. 1812, no. 8, pp. 1007-1022, 2011.

[24] Y. S. Lutzow, C. Gray, and R. Tellam, "15-Deoxy- $\Delta 12,14-$ prostaglandin $\mathrm{J} 2$ induces chemokine expression, oxidative stress and microfilament reorganization in bovine mammary epithelial cells," Journal of Dairy Research, vol. 75, no. 1, pp. 5563, 2008.

[25] J. J. Loor, Kasey M. Moyes, and Massimo Bionaz, "Functional adaptations of the transcriptome to mastitis-causing pathogens: the mammary gland and beyond," Journal of Mammary Gland Biology and Neoplasia, vol. 16, no. 4, pp. 305-322, 2011.

[26] D. McClenahan, R. Krueger, H.-Y. Lee, C. Thomas, M. E. Kehrli Jr., and C. Czuprynski, "Interleukin-8 expression by mammary gland endothelial and epithelial cells following experimental mastitis infection with E. coli," Comparative Immunology, Microbiology and Infectious Diseases, vol. 29, no. 2-3, pp. 127137, 2006.

[27] K. M. Moyes, J. K. Drackley, D. E. Morin et al., "Gene network and pathway analysis of bovine mammary tissue challenged with Streptococcus uberis reveals induction of cell proliferation and inhibition of PPARgamma signaling as potential mechanism for the negative relationships between immune response and lipid metabolism," BMC Genomics, vol. 10, article 542, 2009.

[28] G. C. Gurtner, S. Werner, Y. Barrandon, and M. T. Longaker, "Wound repair and regeneration," Nature, vol. 453, no. 7193, pp. 314-321, 2008.

[29] K. L. Smith, S. E. Stebulis, M. R. Waldron, and T. R. Overton, "Prepartum 2,4-thiazolidinedione alters metabolic dynamics and dry matter intake of dairy cows," Journal of Dairy Science, vol. 90, no. 8, pp. 3660-3670, 2007.

[30] A. P. K. Lo, D. W. Fink, J. B. Williams, and J. Blodinger, "Pharmacokinetic studies of ivermectin: effects of formulation," Veterinary Research Communications, vol. 9, no. 1, pp. 251-268, 1985.

[31] M. C. Lasagno, C. Vissio, E. B. Reinoso et al., "Development of an experimentally induced Streptococcus uberis subclinical mastitis in goats," Veterinary Microbiology, vol. 154, no. 3-4, pp. 376-383, 2012.

[32] K. M. Hultquist and D. P. Casper, "Effects of feeding rumendegradable valine on milk production in late-lactating dairy cows," Journal of Dairy Science, vol. 99, no. 2, pp. 1201-1215, 2016.

[33] M. Bionaz, E. Trevisi, L. Calamari, F. Librandi, A. Ferrari, and G. Bertoni, "Plasma paraoxonase, health, inflammatory conditions, and liver function in transition dairy cows," Journal of Dairy Science, vol. 90, no. 4, pp. 1740-1750, 2007.

[34] E. Trevisi, M. Amadori, S. Cogrossi, E. Razzuoli, and G. Bertoni, "Metabolic stress and inflammatory response in high-yielding, periparturient dairy cows," Research in Veterinary Science, vol. 93, no. 2, pp. 695-704, 2012.

[35] C. B. Jacometo, J. S. Osorio, M. Socha et al., "Maternal consumption of organic trace minerals alters calf systemic and neutrophil mRNA and microRNA indicators of inflammation and oxidative stress," Journal of Dairy Science, vol. 98, no. 11, pp. 7717-7729, 2015. 
[36] A. Katz, S. S. Nambi, K. Mather et al., "Quantitative insulin sensitivity check index: a simple, accurate method for assessing insulin sensitivity in humans," The Journal of Clinical Endocrinology \& Metabolism, vol. 85, no. 7, pp. 2402-2410, 2000.

[37] P. Holtenius and K. Holtenius, "A model to estimate insulin sensitivity in dairy cows," Acta Veterinaria Scandinavica, vol. 49, no. 1, article no. 29, 2007.

[38] E. Schmitt, M. A. Ballou, M. N. Correa, E. J. DePeters, J. K. Drackley, and J. J. Loor, "Dietary lipid during the transition period to manipulate subcutaneous adipose tissue peroxisome proliferator-activated receptor- $\gamma$ co-regulator and target gene expression," Journal of Dairy Science, vol. 94, no. 12, pp. 59135925, 2011.

[39] J. Stingl, C. J. Eaves, I. Zandieh, and J. T. Emerman, "Characterization of bipotent mammary epithelial progenitor cells in normal adult human breast tissue," Breast Cancer Research and Treatment, vol. 67, no. 2, pp. 93-109, 2001.

[40] M. Bionaz and J. J. Loor, "Identification of reference genes for quantitative real-time PCR in the bovine mammary gland during the lactation cycle," Physiological Genomics, vol. 29, no. 3, pp. 312-319, 2007.

[41] P. Cremonesi, R. Capoferri, G. Pisoni et al., "Response of the goat mammary gland to infection with Staphylococcus aureus revealed by gene expression profiling in milk somatic and white blood cells," BMC Genomics, vol. 13, article 540, 2012.

[42] J. Vandesompele, K. De Preter, F. Pattyn et al., "Accurate normalization of real-time quantitative RT-PCR data by geometric averaging of multiple internal control genes," Genome Biology, vol. 3, no. 7, 2002.

[43] S. A. Bustin, V. Benes, J. A. Garson et al., “The MIQE guidelines: minimum information for publication of quantitative real-time PCR experiments," Clinical Chemistry, vol. 55, no. 4, pp. 611-622, 2009.

[44] L. Kamentsky, T. R. Jones, A. Fraser et al., "Improved structure, function and compatibility for cellprofiler: Modular highthroughput image analysis software," Bioinformatics, vol. 27, no. 8, pp. 1179-1180, 2011.

[45] S. Fleige and M. W. Pfaffl, "RNA integrity and the effect on the real-time qRT-PCR performance," Molecular Aspects of Medicine, vol. 27, no. 2-3, pp. 126-139, 2006.

[46] C. Becker, A. Hammerle-Fickinger, I. Riedmaier, and M. W. Pfaffl, "mRNA and microRNA quality control for RT-qPCR analysis," Methods, vol. 50, no. 4, pp. 237-243, 2010.

[47] Y. Kiku, Y. Nagasawa, F. Tanabe, K. Sugawara, A. Watanabe et al., "The cell wall component lipoteichoic acid of Staphylococcus aureus induces chemokine gene expression in bovine mammary epithelial cells," The Journal of Veterinary Medical Science, vol. 78, pp. 1505-1510, 2016.

[48] X. Sun and W. V. Ingman, "Cytokine networks that mediate epithelial cell-macrophage crosstalk in the mammary gland: implications for development and cancer," Journal of Mammary Gland Biology and Neoplasia, vol. 19, no. 2, pp. 191-201, 2014.

[49] G. Bertoni, E. Trevisi, X. Han, and M. Bionaz, "Effects of inflammatory conditions on liver activity in puerperium period and consequences for performance in dairy cows," Journal of Dairy Science, vol. 91, no. 9, pp. 3300-3310, 2008.

[50] P. D. Eckersall, F. J. Young, C. McComb et al., "Acute phase proteins in serum and milk from dairy cows with clinical mastitis," Veterinary Record, vol. 148, no. 2, pp. 35-41, 2001.

[51] G. Bertoni and E. Trevisi, "Use of the liver activity index and other metabolic variables in the assessment of metabolic health in dairy herds," Veterinary Clinics of North America Food Animal Practice, vol. 29, no. 2, pp. 413-431, 2013.

[52] P. Jawor and T. Stefaniak, "Acute Phase Proteins in Cattle," in Acute Phase Proteins as Early Non-Specific Biomarkers of Human and Veterinary Diseases, Francisco Veas, Ed., InTech, 2011.

[53] F. H. D. González, F. Tecles, S. Martínez-Subiela, A. Tvarijonaviciute, L. Soler, and J. J. Cerón, "Acute phase protein response in goats," Journal of Veterinary Diagnostic Investigation, vol. 20, no. 5, pp. 580-584, 2008.

[54] F. Piccioli-Cappelli, A. Minuti, M. Maiocchi, M. Mezzetti, and E. Trevisi, "Effects of protected methionine supplementation during dry period of seasonally synchronized goats on blood parameters and the subsequent lactation," Journal of Animal Science, vol. 94, p. 822, 2016.

[55] J. D. Arthington, S. D. Eicher, W. E. Kunkle, and F. G. Martin, "Effect of transportation and commingling on the acute-phase protein response, growth, and feed intake of newly weaned beef calves," Journal of Animal Science, vol. 81, no. 5, pp. 1120-1125, 2003.

[56] K. M. Moyes, T. Larsen, P. Sørensen, and K. L. Ingvartsen, "Changes in various metabolic parameters in blood and milk during experimental Escherichia coli mastitis for primiparous Holstein dairy cows during early lactation," Journal of Animal Science and Biotechnology, vol. 5, no. 1, p. 47, 2014.

[57] K. M. Moyes, J. K. Drackley, J. L. Salak-Johnson, D. E. Morin, J. C. Hope, and J. J. Loor, "Dietary-induced negative energy balance has minimal effects on innate immunity during a Streptococcus uberis mastitis challenge in dairy cows during midlactation," Journal of Dairy Science, vol. 92, no. 9, pp. 43014316, 2009.

[58] D. Hoeben, C. Burvenich, E. Trevisi et al., "Role of endotoxin and TNF- $\alpha$ in the pathogenesis of experimentally induced coliform mastitis in periparturient cows," Journal of Dairy Research, vol. 67, no. 4, pp. 503-514, 2000.

[59] S. Pyörälä, "Effect of some vehicles used in intramammary mastitis preparations on inflammation indicators in milk," Journal of Veterinary Pharmacology and Therapeutics, vol. 10, no. 3, pp. 248-253, 1987.

[60] E. Trevisi, L. Moscatu, and M. Amadori, "Disease-Predicting and Prognostic Potential of Innate Immune Responses to Noninfectious Stressors: Human and Animal Models," in The Innate Immune Response to Non-infectious Stressors, M. Amadori, Ed., pp. 209-235, Elsevier, The Netherland, 2016.

[61] D. E. Graugnard, K. M. Moyes, E. Trevisi et al., "Liver lipid content and inflammometabolic indices in peripartal dairy cows are altered in response to prepartal energy intake and postpartal intramammary inflammatory challenge," Journal of Dairy Science, vol. 96, no. 2, pp. 918-935, 2013.

[62] F. Piccioli-Cappelli, J. J. Loor, C. J. Seal, A. Minuti, and E. Trevisi, "Effect of dietary starch level and high rumen-undegradable protein on endocrine-metabolic status, milk yield, and milk composition in dairy cows during early and late lactation," Journal of Dairy Science, vol. 97, no. 12, pp. 7788-7803, 2014.

[63] H. N. Ginsberg, Y.-L. Zhang, and A. Hernandez-Ono, "Regulation of plasma triglycerides in insulin resistance and diabetes," Archives of Medical Research, vol. 36, no. 3, pp. 232-240, 2005.

[64] A. T. Mathews, J. E. Rico, N. T. Sprenkle, A. L. Lock, and J. W. McFadden, "Increasing palmitic acid intake enhances milk production and prevents glucose-stimulated fatty acid disappearance without modifying systemic glucose tolerance in mid-lactation dairy cows," Journal of Dairy Science, vol. 99, no. 11, pp. 8802-8816, 2016. 
[65] G. S. Hotamisligil, "Mechanisms of TNF- $\alpha$-induced insulin resistance," Experimental and Clinical Endocrinology and Diabetes, vol. 107, no. 2, pp. 119-125, 1999.

[66] S. Kushibiki, K. Hodate, H. Shingu et al., "Insulin resistance induced in dairy steers by tumor necrosis factor alpha is partially reversed by 2,4-thiazolidinedione," Domestic Animal Endocrinology, vol. 21, no. 1, pp. 25-37, 2001.

[67] K. Yuan, J. K. Farney, L. K. Mamedova, L. M. Sordillo, and B. J. Bradford, "TNF $\alpha$ altered inflammatory responses, impaired health and productivity, but did not affect glucose or lipid metabolism in early-lactation dairy cows," PLoS ONE, vol. 8, no. 11, article e80316, 2013.

[68] J. P. Goff and R. L. Horst, "Physiological changes at parturition and their relationship to metabolic disorders," Journal of Dairy Science, vol. 80, no. 7, pp. 1260-1268, 1997.

[69] S. Atasever, U. Sen, and H. Onder, "A study on the determination of body condition score and somatic cell count in Turkish Saanen goats," Journal of Applied Animal Research, vol. 43, no. 4, pp. 445-449, 2015.

[70] V. S. Jain, D. K. Vora, and C. S. Ramaa, "Thiazolidine-2,4diones: progress towards multifarious applications," Bioorganic and Medicinal Chemistry, vol. 21, no. 7, pp. 1599-1620, 2013.

[71] S. Nazreen, M. S. Alam, H. Hamid et al., "Design, synthesis, and biological evaluation of thiazolidine-2,4-dione conjugates as PPAR- $\gamma$ agonists," Archiv der Pharmazie, vol. 348, no. 6, pp. 421-432, 2015.

[72] K. L. Smith, W. R. Butler, and T. R. Overton, "Effects of prepartum 2,4-thiazolidinedione on metabolism and performance in transition dairy cows," Journal of Dairy Science, vol. 92, no. 8, pp. 3623-3633, 2009.

[73] K. M. Schoenberg and T. R. Overton, "Effects of plane of nutrition and 2,4-thiazolidinedione on insulin responses and adipose tissue gene expression in dairy cattle during late gestation," Journal of Dairy Science, vol. 94, no. 12, pp. 60216035, 2011.

[74] A. R. Yousefi, H. Kohram, A. Zare Shahneh, M. J. Zamiri, and A. A. Fouladi-Nashta, "Effects of dietary supplementation of pioglitazone on metabolism, milk yield, and reproductive performance in transition dairy cows," Theriogenology, vol. 85, no. 9, pp. 1540-1548, 2016.

[75] K. J. Harvatine, J. W. Perfield II, and D. E. Bauman, "Expression of enzymes and key regulators of lipid synthesis is upregulated in adipose tissue during CLA- induced milk fat depression in dairy cows," Journal of Nutrition, vol. 139, no. 5, pp. 849-854, 2009.

[76] M. K. Mohommad, Z. Zhou, M. Cave, A. Barve, and C. J. McClain, "Zinc and liver disease," Nutrition in Clinical Practice, vol. 27, no. 1, pp. 8-20, 2012.

[77] P. Rainard and C. Riollet, "Innate immunity of the bovine mammary gland," Veterinary Research, vol. 37, no. 3, pp. 369400, 2006.

[78] S. J. Klebanoff, A. J. Kettle, H. Rosen, C. C. Winterbourn, and W. M. Nauseef, "Myeloperoxidase: a front-line defender against phagocytosed microorganisms," Journal of Leukocyte Biology, vol. 93, no. 2, pp. 185-198, 2013.

[79] Y. Kato, "Neutrophil myeloperoxidase and its substrates: formation of specific markers and reactive compounds during inflammation," Journal of Clinical Biochemistry and Nutrition, vol. 58, no. 2, pp. 99-104, 2016.

[80] F. A. Mayyas, M. I. Al-Jarrah, K. S. Ibrahim, and K. H. Alzoubi, "Level and significance of plasma myeloperoxidase and the neutrophil to lymphocyte ratio in patients with coronary artery disease," Experimental and Therapeutic Medicine, vol. 8, no. 6, pp. 1951-1957, 2014.

[81] A. P. Kumar, F. J. Piedrafita, and W. F. Reynolds, “Peroxisome proliferator-activated Receptor $\gamma$ ligands regulate myeloperoxidase expression in macrophages by an estrogen-dependent mechanism involving the -463GA promoter Polymorphism," Journal of Biological Chemistry, vol. 279, no. 9, pp. 8300-8315, 2004.

[82] H. R. Liu, L. Tao, E. Gao et al., "Rosiglitazone inhibits hypercholesterolaemia-induced myeloperoxidase upregulation-a novel mechanism for the cardioprotective effects of PPAR agonists," Cardiovascular Research, vol. 81, no. 2, pp. 344-352, 2009.

[83] A. Croasdell, P. F. Duffney, N. Kim, S. H. Lacy, P. J. Sime, and R. P. Phipps, "PPAR $\gamma$ and the innate immune system mediate the resolution of inflammation,” PPAR Research, vol. 2015, Article ID 549691, 20 pages, 2015.

[84] V. Loria, I. Dato, F. Graziani, and L. M. Biasucci, "Myeloperoxidase: a new biomarker of inflammation in ischemic heart disease and acute coronary syndromes," Mediators of Inflammation, vol. 2008, Article ID 135625, 4 pages, 2008.

[85] J. M. Moreno-Navarrete and J. M. Fernández-Real, "Adipocyte Differentiation," in Adipose Tissue Biology, M. E. Symonds, Ed., Springer Science + Business Media LLC, 2012.

[86] A. Hosseini, M. R. Tariq, F. T. Da Rosa et al., "Insulin sensitivity in adipose and skeletal muscle tissue of dairy cows in response to dietary energy level and 2,4-thiazolidinedione (TZD)," PLoS ONE, vol. 10, no. 11, article e0142633, 2015. 


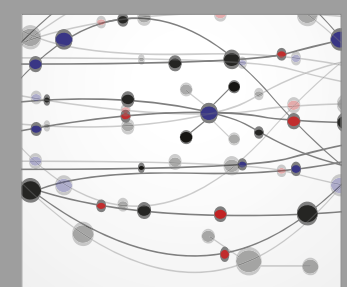

The Scientific World Journal
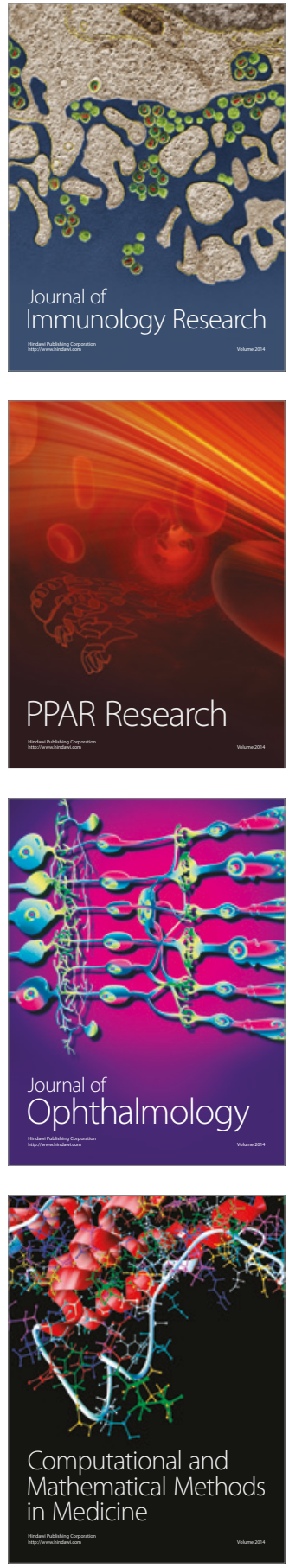

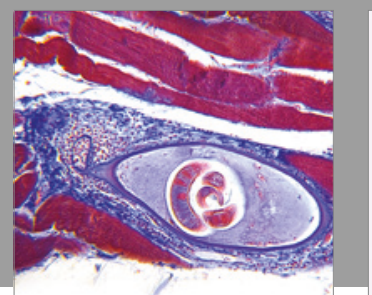

Gastroenterology Research and Practice
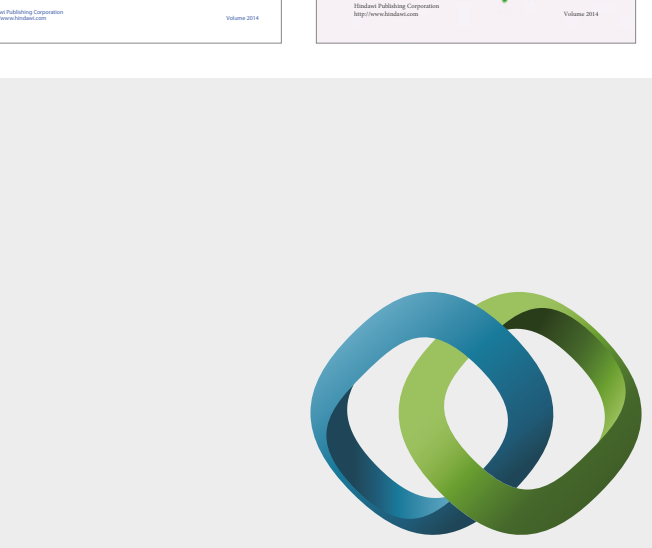

\section{Hindawi}

Submit your manuscripts at

https://www.hindawi.com
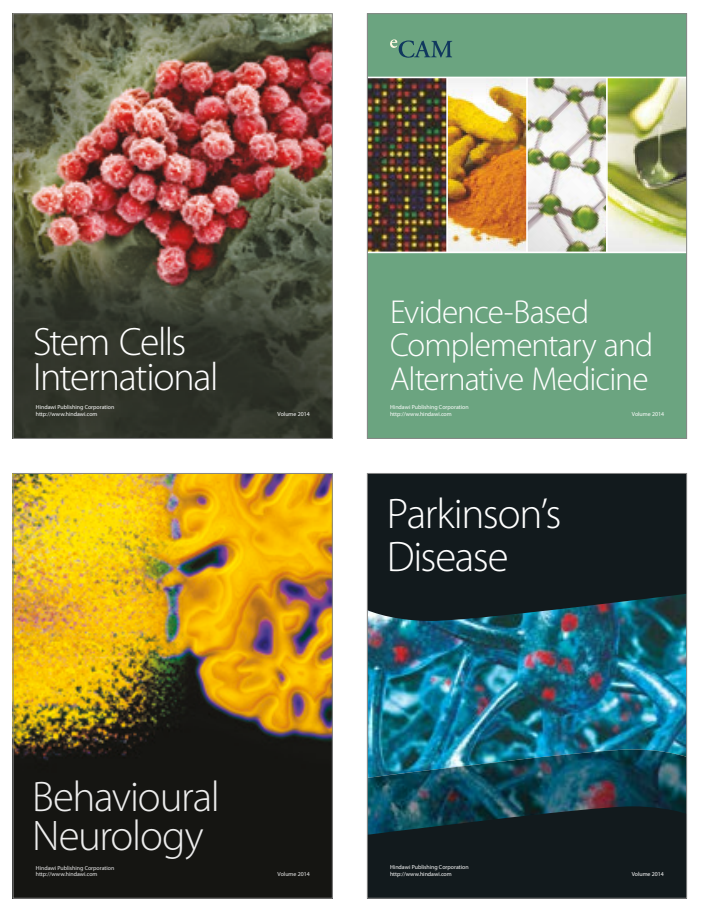
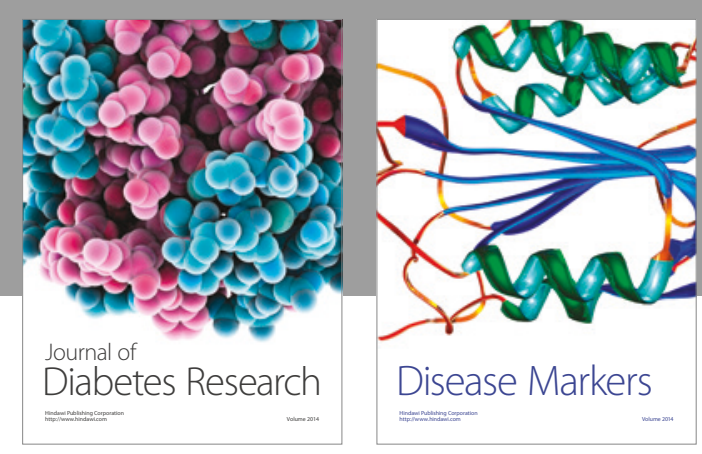

Disease Markers
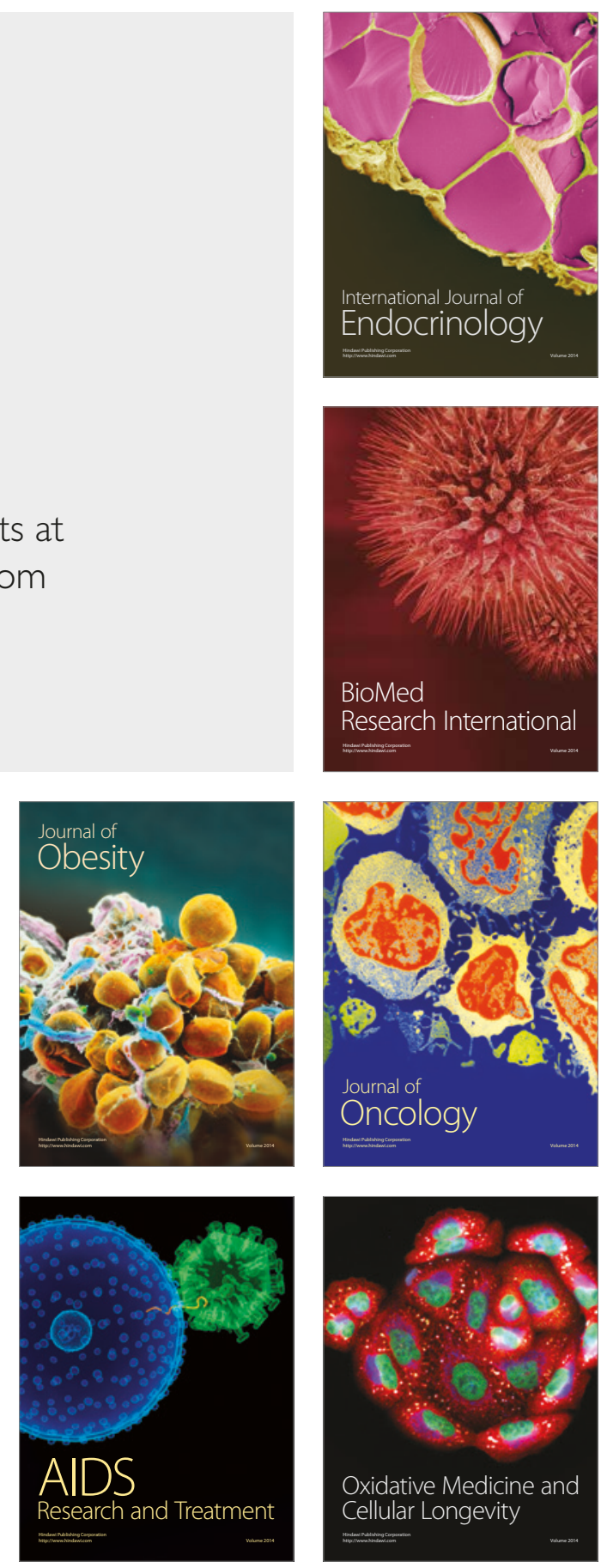